Accepted version. Published as: Wyrzykowski et al., Basic creep of cement paste at early age - the role of cement hydration. Cem Concr Res (2019) 116: 191-201

https://doi.org/10.1016/j.cemconres.2018.11.013

\title{
Basic creep of cement paste at early age - the role of cement hydration
}

Mateusz Wyrzykowski ${ }^{1 *}$, Karen L. Scrivener ${ }^{2}$, Pietro Lura ${ }^{1,3}$

${ }^{1}$ Empa, Swiss Federal Laboratories for Materials Science and Technology, Switzerland

${ }^{2}$ Laboratory of Construction Materials (LMC), EPF Lausanne, Switzerland

${ }^{3}$ Institute for Building Materials (IfB), ETH Zurich, Switzerland

* corresponding author: mateusz.wyrzykowski@empa.ch

\section{Abstract}

In this work, the uniaxial creep in compression during the first days of hydration is studied experimentally on cement pastes with w/c of 0.50 . In order to assess the effect of the evolving microstructure on creep, the so-called equivalent systems are employed. In these systems, part of the otherwise unhydrated cement is replaced with inert filler (quartz powder). With this approach, non-aging systems are obtained that can emulate specific microstructural features of the real hydrating systems.

Despite the very similar elastic Young's moduli of the real and their corresponding equivalent systems, the real hydrating systems experienced much higher creep in the first weeks after loading than the equivalent, inert systems. The differences in creep could be explained either by possibly different morphologies of the hydrates in the two types of systems, intrinsic aging or with the active role of the hydration process in increasing creep (dissolution theory of creep).

Keywords: basic creep; cement paste; hydration; aging; viscoelasticity

This document is the accepted manuscript version of the following article: wyrzykowski, M., Scrivener, K., \& Lura, P. (2019). Basic creep of cement paste at early age - the role of cement hydration. Cement and Concrete Research, 116, 191-201. https://doi.org/10.1016/j.cemconres.2018.11.013 
Accepted version. Published as: Wyrzykowski et al., Basic creep of cement paste at early age - the role of cement hydration. Cem Concr Res (2019) 116: 191-201

https://doi.org/10.1016/j.cemconres.2018.11.013

\section{Introduction}

Understanding creep and relaxation of concrete at early age is of utmost importance for predicting deformations, stress development and cracking, both due to external loads and due to hygral shrinkage or temperature changes [1]. Creep and relaxation of concrete are consequences of viscoelastic/viscoplastic behavior of the cement paste restrained by elastic aggregates, e.g. [2]. At a still lower microstructural level, calcium silicate hydrate $(\mathrm{C}-\mathrm{S}-\mathrm{H})$, a major component of hardened Portland cement paste, has been identified in nanoindentation tests (e.g. [3-5]) as being responsible in major part for the viscoelastic behavior of cement paste. Even though these phenomena have been studied extensively for almost a century [1], creep and relaxation are among the most challenging topics in the field of concrete material science.

A number of theories to explain the fundamental mechanisms of creep of cement paste at early age and aging of creep have been proposed, e.g., solidification [6], relaxation of microprestress [6], clinker dissolution [7], dissolution of C-S-H [8], different forms of C-S-H dislocation/sliding [5, 6, 9], polymerization of C-S-H [10, 11], or microcracking and seepage of water into the cracks [12].

One of the most popular theories used nowadays for describing aging of creep (i.e. the evolution of viscoelastic properties in time resulting in lower creep at later ages) is the solidification theory by Bažant and Prasannan [10]. The solidification theory explains aging of creep as the effect of deposition of new hydration products that are characterized by intrinsically non-aging creep behavior. With the increasing volume of load-bearing hydrates, redistribution of load takes place. Later, Bažant et al. [6] proposed that the relaxation of the microprestress acting across the shear sites in the nanopores could be responsible for long-term aging (microprestress-solidification theory).

Inherent aging of the hydrated 'gel' in addition to solidification has also been proposed $[13,14]$. Another alternative description has been proposed recently by Li et al. [7]. They performed numerical microstructural simulations showing that time-lapsed dissolution of anhydrous cement (elastic clinker) 
Accepted version. Published as: Wyrzykowski et al., Basic creep of cement paste at early age - the role of cement hydration. Cem Concr Res (2019) 116: 191-201

https://doi.org/10.1016/j.cemconres.2018.11.013

and the resulting time-lapsed elastic deformation can manifest in apparent creep response at the macroscopic scale even in the absence of any intrinsically creeping components.

Understanding the creep of cementitious materials at early age is particularly challenging due to the rapidly developing material properties, which results in the evolution of the elastic properties (hardening) and at the same time affect the evolution of the creep behavior (aging). Furthermore, because the actual measurements of creep are invariably time-lapsed and hence take place simultaneously with large changes in the microstructure caused by the ongoing cement hydration, the determined creep/relaxation properties cannot by definition correspond to a single time instant, e.g., the time of loading. Moreover, in concrete at low water-to-cement ratio $(w / c)$ or concrete exposed to drying, creep deformations take place simultaneously to deformations due to hygral shrinkage [15], which introduces an additional complexity in both the measurements (e.g. it requires reference, unloaded samples) and especially in the analysis of the data. A special and particularly complex case is the assessment of the creep contribution to autogenous shrinkage, where the load is not an imposed mechanical load but acts in the form of a constantly-increasing pore fluid pressure (self-desiccation) [1417].

The fundamental problem of measuring (aging) creep in an evolving cementitious material at early age can be addressed in two ways:

- First, creep measurements can be performed at short time scale. Nanoindentation $[3,4]$ or microindentation $[18,19]$ tests in which the creep response lasts seconds to minutes fall into this category. Nanoindentation tests, however, meet serious difficulties due to problems in probing single phases $[20,21]$, which may result in determination of effective properties that are due to a convoluted response of viscoelastic (C-S-H) and elastic (e.g., clinker or crystalline hydration products) components. Further, the nanoindentation and microindentation tests are based on high stress levels applied by an indenter on a small probed volume, in particular for the commonly applied sharp indenters (e.g., Berkovich pyramidal probe), but also for spherical and flat indenters [22]. As a consequence, plastic deformation cannot be avoided during the 
Accepted version. Published as: Wyrzykowski et al., Basic creep of cement paste at early age - the role of cement hydration. Cem Concr Res (2019) 116: 191-201

https://doi.org/10.1016/j.cemconres.2018.11.013

loading stage [22] and hence data interpretation aimed at accounting for the plasticity effects requires a series of assumptions that maybe further sources of error. Another issue related to the geometry of the commonly-used conical indenters is the non-constant (decreasing) stress in time as the penetration depth of an indenter increases [4]. Another type of short-term creep measurements are macroscopic measurements of creep lasting a short time compared to the kinetics of cement hydration. In a recent work [23], Irfan-ul-Hassan et al. applied compressive creep tests on cement pastes during the first days of hydration. The loading steps lasted 3 minutes each and were spaced at $1 \mathrm{~h}$ intervals, taking advantage of the fact that the material properties and hence also the creep properties do not change considerably during each test (non-aging creep), while they change between the consecutive tests (apparent or intrinsic aging). In this way, the evolution of the creep properties (creep modulus) as a function of hydration degree was obtained.

- A second approach for assessing creep of cementitious materials at early age would require arresting cement hydration and performing creep measurements on a static microstructure. Arresting hydration is commonly used for measurements of e.g. porosimetry, microscopy, thermogravimetry or X-ray diffraction, etc. and in virtually all cases is based on removing the water from the microstructure so that any remaining unhydrated binder will not react further $[24,25]$. However, in addition to possibly inducing damage of the microstructure by drying, creep measured on a cement paste from which all water has been removed is expected to be considerably different, based on the commonly-reported strong dependence of creep upon moisture state, see e.g. $[19,26,27]$. This difference could be due to the role of water acting as lubricant in the sliding of the hydration products or due to the role of (confining) pore pressure on the creep process $[6,9,28]$.

Another method for obtaining static cementitious microstructures has been proposed recently by Termkhajornkit et al. [29], the so-called microstructurally-designed, mimic, or equivalent systems. Equivalent systems are cement pastes where part of the cement is replaced by inert filler (e.g., fine quartz 
Accepted version. Published as: Wyrzykowski et al., Basic creep of cement paste at early age - the role of cement hydration. Cem Concr Res (2019) 116: 191-201

https://doi.org/10.1016/j.cemconres.2018.11.013

powder) [29]. The amount of filler replacing the cement in the equivalent system corresponds to the amount of unhydrated cement in a real mix at a desired hydration stage to be mimicked. The equivalent system is allowed to hydrate for a long time (e.g. 3 months [30]) so that the obtained microstructure is composed only of fully-hydrated cement paste (with the corresponding porosity) and filler (representing the unhydrated cement in a real system). A schematic representation of the equivalent system compared to the real system is presented in Fig. 1. In this figure, Powers's model of the volumetric composition of a w/c 0.50 cement paste [31] is used. The figures are cropped to the hydration degree of 0.52 reached by the real paste after about $1.5 \mathrm{~d}$ (see Table 1). In the equivalent system, where all cement has hydrated (and the system is thus inert), the volumetric composition is similar to that in the real system.

By using this approach, a static (non-aging) system is obtained that is capable of emulating specific characteristics of a real system at the corresponding age, e.g., porosity, strength, elastic properties, fracture properties [30, 32, 33]. Equivalent systems have been also used in [34] for assessing drying shrinkage of mortars at early ages. This paper studies the application of equivalent systems for measuring creep at early ages. 
Accepted version. Published as: Wyrzykowski et al., Basic creep of cement paste at early age - the role of cement hydration. Cem Concr Res (2019) 116: 191-201

https://doi.org/10.1016/j.cemconres.2018.11.013

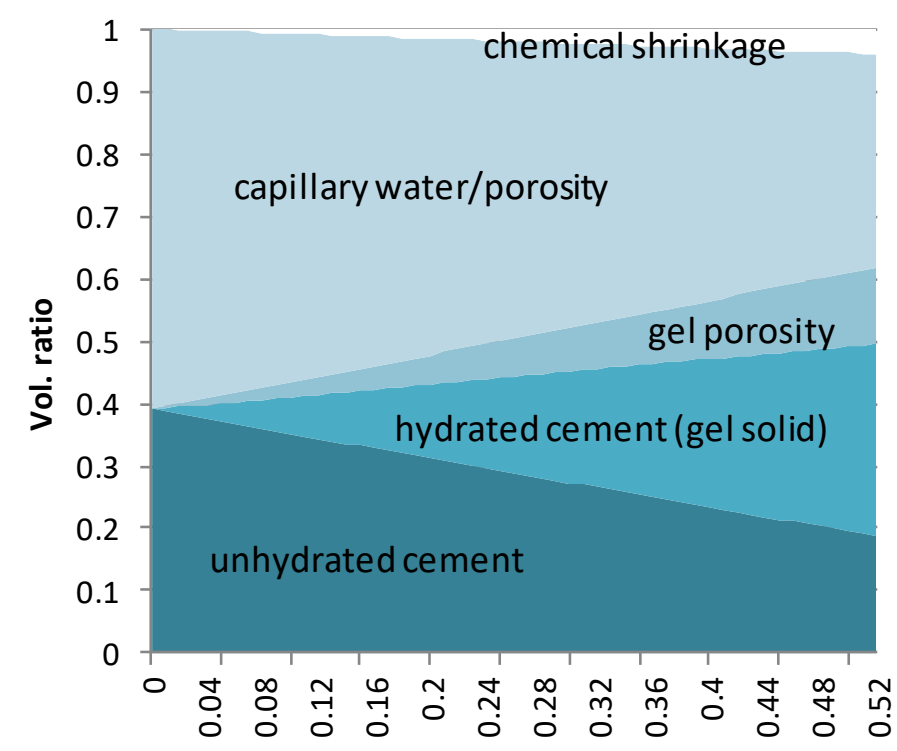

a

Hydration degree

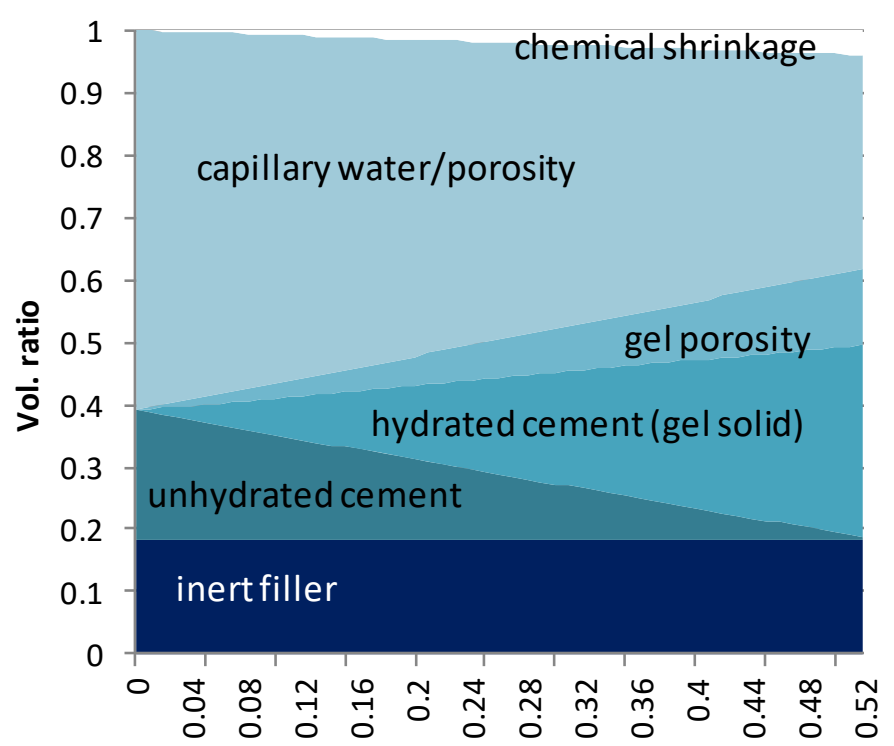

b

Equivalent hydration degree

Fig. 1. Schematic representation of the volumetric composition and its evolution during hydration

(based on Powers' model [31]) of: a) a real system (w/c 0.50 cement paste) - the maximum hydration

degree presented, 0.525 , corresponds to the age of $1.5 \mathrm{~d}$ (note that the system can hydrate further), b)

equivalent $1.5 \mathrm{~d}$ system in which, after all cement has reacted, the porosity and volume of solids

correspond to those in the real system at $1.5 \mathrm{~d}$. The inert filler (quartz powder) in the equivalent system has the same volume as the unreacted cement in the real system at the corresponding age. 
Accepted version. Published as: Wyrzykowski et al., Basic creep of cement paste at early age - the role of cement hydration. Cem Concr Res (2019) 116: 191-201

https://doi.org/10.1016/j.cemconres.2018.11.013

In this study, measurements of creep in compression were performed on both equivalent systems and real systems (cement pastes at w/c 0.50$)$ loaded at different early ages of hydration $(1.5,3$ and $7 \mathrm{~d}$ ) to study creep mechanisms at early age. All the measurements were performed on sealed samples (basic creep). In a preliminary step, the equivalent systems were designed, which involved the estimation of the amount of quartz filler needed to replace the unhydrated cement at the desired hydration stages; this was achieved with scanning electron microscopy (SEM) and isothermal calorimetry. The evolution of the mechanical properties (compressive strength and static elastic Young's modulus in compression) was measured on the real systems and on the corresponding equivalent systems. After ensuring that the Young's modulus of the real and equivalent systems closely matched, measurements of creep in compression followed. The results obtained were used to 1) verify whether the equivalent systems can be used as model systems to emulate creep of cement paste at early age, and 2) to provide insight or experimental verification into different theories explaining creep.

\section{Materials and methods}

\subsection{Materials and mix design}

The basic composition tested here was cement paste of w/c 0.5 (by mass, corresponding to 1.565 by volume) prepared with white Portland cement CEM I 52.5 R (Aalborg Portland) and deionized water. The w/c 0.50 paste corresponds to the real system. The oxide composition of the cement was (by mass \%): $\mathrm{SiO}_{2}$ 24.37, $\mathrm{Al}_{2} \mathrm{O}_{3}$ 1.97, $\mathrm{Fe}_{2} \mathrm{O}_{3}$ 0.32, $\mathrm{CaO} 68.48$ (free $\mathrm{CaO}$ 1.35), $\mathrm{MgO} 0.70, \mathrm{~K}_{2} \mathrm{O} 0.09, \mathrm{Na}_{2} \mathrm{O}$ 0.16, $\mathrm{SO}_{3} 2.07$. The phase composition of the cement measured with quantitative X-ray diffractometry (QXRD) was (by mass \%): $\mathrm{C}_{3} \mathrm{~S} 71, \mathrm{C}_{2} \mathrm{~S} 21, \mathrm{C}_{3} \mathrm{~A} 3.2, \mathrm{C}_{4} \mathrm{AF} 0.20, \mathrm{CH} 0.50$, anhydrite/gypsum 2.0, calcite+dolomite 0.50. The cement had Blaine fineness of $3940 \mathrm{~cm}^{2} / \mathrm{g}$, density of $3.13 \mathrm{~g} / \mathrm{cm}^{3}$ and median particle size $d_{50}$ equal to 7 $\mu \mathrm{m}$ (laser diffraction).

The equivalent systems had at the time of mixing the same volumetric water-to-solid ratio (where solid is the sum of quartz and cement) as the real system, with part of the cement replaced by fine quartz to 
Accepted version. Published as: Wyrzykowski et al., Basic creep of cement paste at early age - the role of cement hydration. Cem Concr Res (2019) 116: 191-201

https://doi.org/10.1016/j.cemconres.2018.11.013

emulate the volume of unhydrated cement present in real systems at $1.5 \mathrm{~d}, 3 \mathrm{~d}$ and $7 \mathrm{~d}$ (for details see [30]), see Table 1 and section 2.2.

The fine quartz powder used as cement replacement was Quartz Flour C400 (Sibelco) with >99\% by mass of crystalline $\mathrm{SiO}_{2}$, a density of $2.65 \mathrm{~g} / \mathrm{cm}^{3}$ and median particle size $d_{50}$ equal to $12 \mu \mathrm{m}$. The same quartz as in [30] was used, where it was shown that it had negligible pozzolanic reactivity.

Different samples were tested for creep and mechanical properties measurements (see the following sections). The equivalent systems were demolded $2 \mathrm{~d}$ after casting and cured for at least $90 \mathrm{~d}$, whereas the real systems were demolded at $1 \mathrm{~d}$ and cured until the corresponding testing/loading age. After demolding, the samples were wrapped in several layers of food wrap that was sprayed with water to provide curing conditions close to $100 \% \mathrm{RH}$ and kept sealed until the age of testing. Mixing took place in climate-controlled room at $21 \pm 0.3^{\circ} \mathrm{C}$, while curing and creep measurements at $20 \pm 0.3^{\circ} \mathrm{C}$.

The age in the name of the systems corresponds to the age of first loading for the real systems, and for the equivalent systems it refers to the equivalent age of these systems.

\subsection{SEM and isothermal calorimetry measurements for mix design of equivalent systems}

The percentage of cement replacement in the equivalent systems (see Table 1) was primarily estimated based on SEM measurements of the unhydrated cement fraction in the real systems.

The cement pastes were mixed for $2 \mathrm{~min}$ at $450 \mathrm{rpm}$ in a vacuum mixer (Twister evolution by Renfert) to minimize the presence of entrained air in the sections used in microscopy. After mixing, the real systems were poured into cylindrical plastic containers (Ø32 mm, height $60 \mathrm{~mm}$ ). The cylinders containing cement paste were next placed on a rotating drum and rotated at a $2 \mathrm{rpm}$ speed for $8 \mathrm{~h}$ (i.e. beyond setting time). The rotation was aimed at avoiding segregation of the pastes.

At the desired age (1, 3 and $7 \mathrm{~d})$, the cylinders were cut into disks of $10-\mathrm{mm}$ thickness and immersed in isopropanol for $4 \mathrm{~d}$ to arrest cement hydration. The volume of isopropanol was several times larger than that of the samples. The isopropanol was subsequently removed by drying the samples in an oven at 40 ${ }^{\circ} \mathrm{C}$ for $4 \mathrm{~d}$. The samples were next impregnated with epoxy resin under vacuum and polished using a 
Accepted version. Published as: Wyrzykowski et al., Basic creep of cement paste at early age - the role of cement hydration. Cem Concr Res (2019) 116: 191-201

https://doi.org/10.1016/j.cemconres.2018.11.013

diamond suspension. At that point, the samples were coated with carbon and SEM images in backscattered electron mode (BSE) were taken at magnification $500 \times$. The unhydrated cement grains could be easily identified on the micrographs, see Fig. 2, and were thus segmented by simple thresholding. The relative area occupied by the grains on polished sections is an estimator of the volumetric fraction occupied by the unhydrated cement in the pastes (Delesse principle). At least 12 micrographs per sample were analyzed and the scatter (standard deviation) of the determined fractions corresponded to less than \pm 0.03 of the estimated degree of hydration (see Table 1).

Additionally, isothermal calorimetry was measured on the real system. Cement paste directly after mixing was placed in duplicate glass vials (about $6 \mathrm{~g}$ per vial) and measured in a TAM-Air isothermal calorimeter at $20 \pm 0.1^{\circ} \mathrm{C}$. The degree of hydration was determined from the cumulative heat normalized with the potential heat of hydration, $460 \mathrm{~J} / \mathrm{g}$ of cement. The latter value was determined based on the phase composition of the cement (see section 2.1) and the hydration enthalpy of individual phases [35].

The estimation of the evolution of the degree of hydration based on the SEM-BSE measurements and on isothermal calorimetry are presented in Fig. 3 and Table 1. The differences between the two methods in the estimated degree of hydration for the youngest sample (hydration stopped from $1 \mathrm{~d}$ ) are discussed in section 3.1 .

The difference in fineness between the quartz filler in equivalent systems and the original unhydrated cement in the real systems was relatively small. No special adjustment of the particle size distribution of the quartz filler was made that would make it closer to the unreacted cement in the real system. A negligible effect of the small differences of fineness between the cement and the filler on the mechanical behavior was assumed based on the original work by Termkhajornkit et al. [29] who reported that the fineness had minor effect on the relation between hydration degree and porosity. This assumption is confirmed by the good agreement of the strength and elastic properties between the equivalent and real systems reported in the following sections and in the previous studies [30, 32]. 
Accepted version. Published as: Wyrzykowski et al., Basic creep of cement paste at early age - the role of cement hydration. Cem Concr Res (2019) 116: 191-201

https://doi.org/10.1016/j.cemconres.2018.11.013
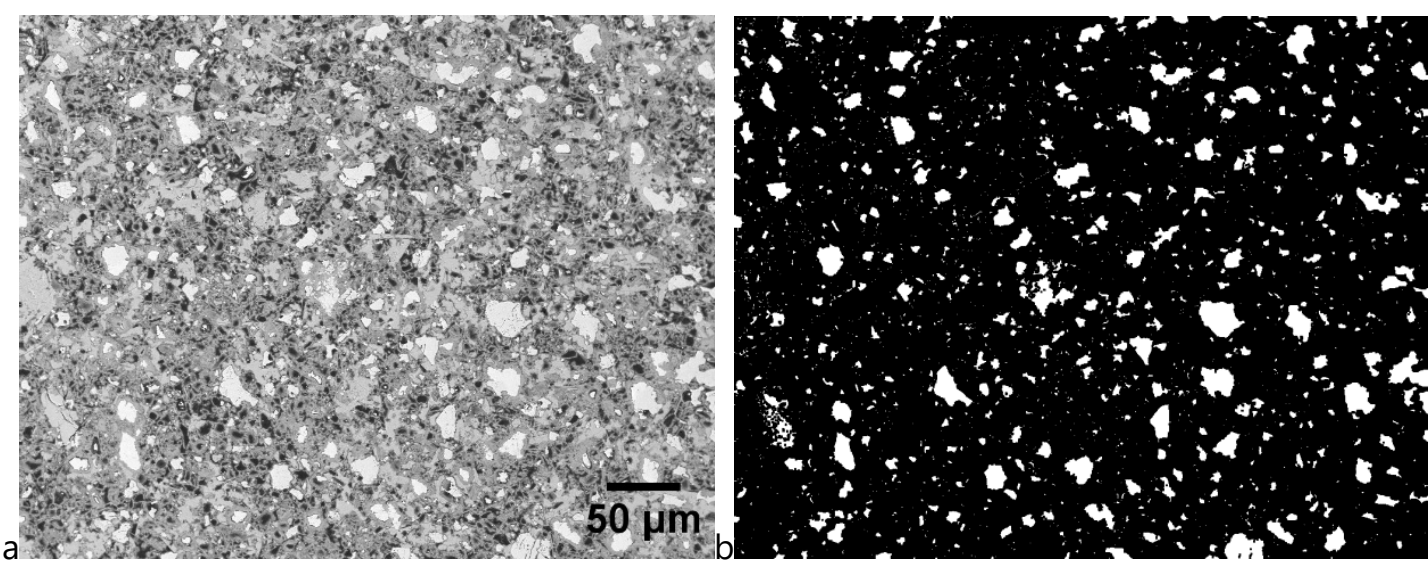

Fig. 2. a) SEM-BSE micrograph of polished w/c 0.50 cement paste sample with hydration arrested at the age of $3 d$; b) segmented unhydrated cement grains (thresholding).

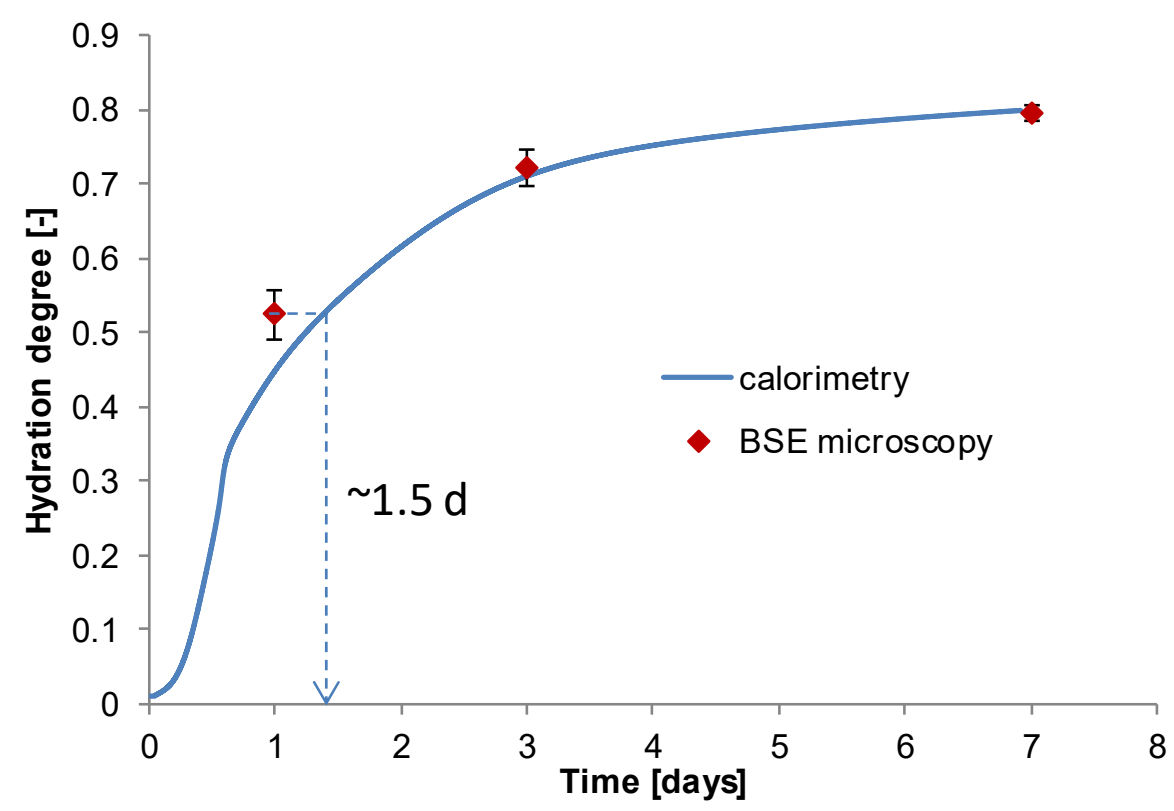

Fig. 3. Evolution of hydration degree in a w/c 0.50 cement paste estimated based on SEM-BSE microscopy and isothermal calorimetry (with estimated potential heat of $460 \mathrm{~J} / \mathrm{g}$ ). Error bars correspond to standard deviation; for the calorimetry data, the difference between the duplicate samples was 0.001 hydration degree at most (not shown). 
Accepted version. Published as: Wyrzykowski et al., Basic creep of cement paste at early age - the role of cement hydration. Cem Concr Res (2019) 116: 191-201

https://doi.org/10.1016/j.cemconres.2018.11.013

Table 1. Estimated hydration degree in the real systems and composition of the corresponding equivalent systems

\begin{tabular}{|l|l|l|l|}
\hline Hydration degree in the real systems / Age & $\mathbf{1 . 5} \mathbf{d}$ & $\mathbf{3 ~ d}$ & $\mathbf{7 ~ d ~}$ \\
\hline Hydration degree - SEM-BSE & $0.52 \pm 0.03^{*}$ & $0.72 \pm 0.02$ & $0.79 \pm 0.01$ \\
\hline Hydration degree - isothermal calorimetry & 0.54 & 0.71 & 0.79 \\
\hline
\end{tabular}

\section{Composition of the equivalent systems (mass)}

\begin{tabular}{|l|l|l|l|}
\hline Cement & 1.000 & 1.000 & 1.000 \\
\hline Quartz (emulates unhydrated cement) & 0.766 & 0.325 & 0.218 \\
\hline Water & 0.953 & 0.692 & 0.629 \\
\hline
\end{tabular}

\section{Composition of the equivalent systems (volume)}

\begin{tabular}{|l|l|l|l|}
\hline Cement & 0.525 & 0.722 & 0.795 \\
\hline Quartz (emulates unhydrated cement) & 0.475 & 0.278 & 0.205 \\
\hline Water & 1.565 & 1.565 & 1.565 \\
\hline
\end{tabular}

* in this system hydration was stopped for the SEM measurements already from $1 \mathrm{~d}$, see section 3.1 .

\subsection{Strength and elastic modulus}

Compressive strength and static elastic Young's modulus in compression were measured on prisms $25 \times 25 \times 100 \mathrm{~mm}^{3}$ (sample size adapted for cement paste from the original $40 \times 40 \times 160 \mathrm{~mm}^{3}$ prescribed for mortars). The samples were cast in stainless steel molds and cured at $>95 \% \mathrm{RH}$ and $20 \pm 0.3{ }^{\circ} \mathrm{C}$ until demolding (see section 2.1). The compressive strength was measured on triplicate samples (two halves of one prism were tested for each sample) based on the EN 196 standard, while the elastic modulus was measured on triplicate samples based on the EN 12390-13:2013 standard. Averaged results are presented together with standard deviation. 
Accepted version. Published as: Wyrzykowski et al., Basic creep of cement paste at early age - the role of cement hydration. Cem Concr Res (2019) 116: 191-201

https://doi.org/10.1016/j.cemconres.2018.11.013

\subsection{Creep measurements}

The creep in compression was measured with gravitational creep stations with levers, see Fig. 4. In order to reach the necessary load, lead plates were suspended from the levers. Before testing the actual specimens, the loads were adjusted using a load cell by placing an appropriate number of lead plates and fine adjusting the lengths of the levers.

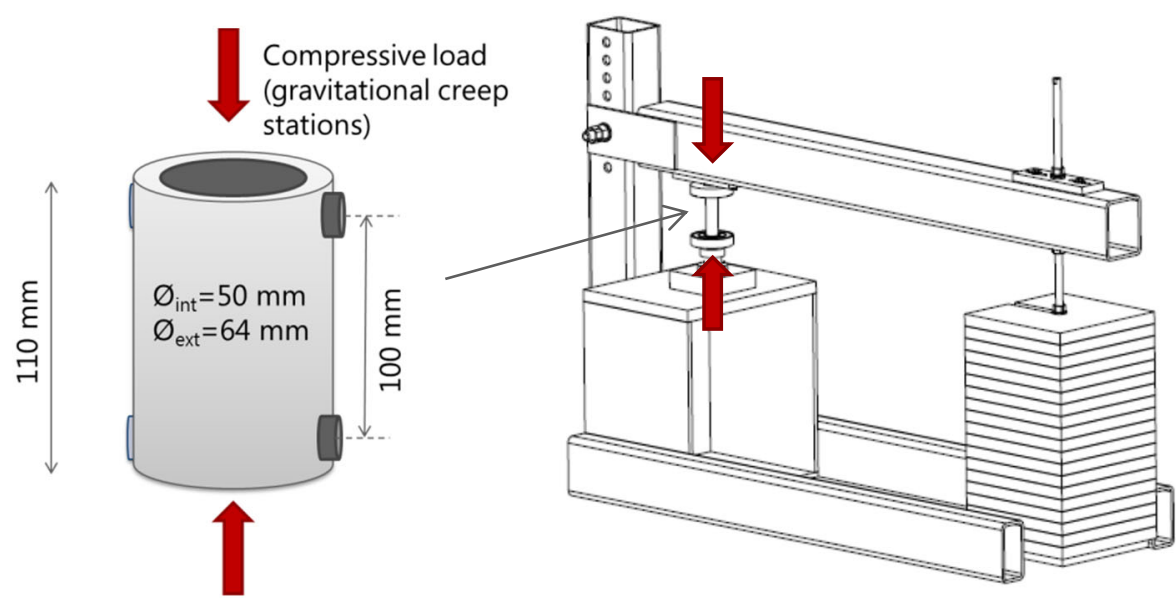

Fig. 4. Samples used in measurements of creep in compression (left) and gravitational creep loading station (right).

The specimens were hollow cylinders prepared in molds made of two PVC tubes of different diameters fixed to a steel base. The hollow cylinder geometry (Fig. 4) was chosen in order to limit buckling/tipping over in compression, while at the same time minimizing the section area of the sample (due to the limited load capacity of the gravitational creep setups). The cycles of loading and unloading applied to the samples lasted in general approximately 28 and $14 \mathrm{~d}$, respectively, Fig. 5. For some samples, longer cycles of loading were applied. The load was applied within a time window of about 5-10 seconds by means of a thread and nut system that connects the hanger on which the lead plates are laid with the lever. The specimens were loaded to $20 \%$ of the compressive strength $\left(f_{c}\right)$ of the cement paste at the age of first loading (see Fig. 5 and Fig. 6a). In order to determine the necessary load, the section area of 
Accepted version. Published as: Wyrzykowski et al., Basic creep of cement paste at early age - the role of cement hydration. Cem Concr Res (2019) 116: 191-201

https://doi.org/10.1016/j.cemconres.2018.11.013

the samples was determined first. It was obtained by scanning the samples standing on a flatbed scanner and next determining the area from the segmented scans. The section area of each sample was about $1200 \mathrm{~mm}^{2}$ and the difference between the top and the bottom sides was $20 \mathrm{~mm}^{2}$ at most. For the determined areas the necessary mass was in the range $\sim 150-245 \mathrm{~kg}$, resulting in loads applied on the samples in the range 7.5 to $12 \mathrm{kN}$ (adjusted with accuracy $\pm 0.01 \mathrm{kN}$ ). The uncertainty of the applied stress (resulting from the differences in the cross-section area within each sample and from the uncertainty of the applied force) was relatively small, see error bars in Fig. 5.

Before applying the full load and during unloading stages, the samples were loaded with about 0.25 $\mathrm{MPa}$ (corresponding to the mass of the lever without lead plates); the deformations are referred to this preloaded state. The deformations were measured by means of manual displacement transducers with $0.001 \mathrm{~mm}$ resolution on metal markers glued to the opposite sides of the specimens at $100 \mathrm{~mm}$ gauge distance (two measurements per sample, see Fig. 4). Two samples were measured for each tested system, except for the real system loaded at $7 \mathrm{~d}$, where only one sample was used (the companion sample broke during preparation).

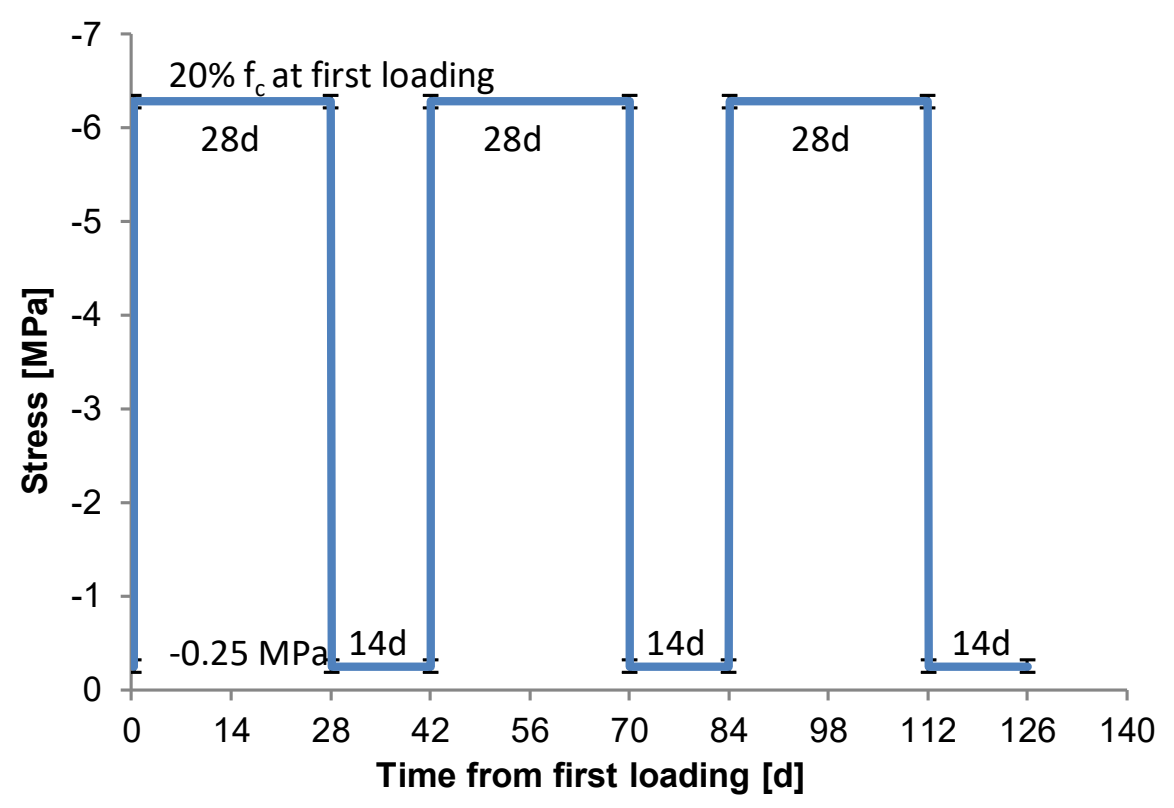

Fig. 5. Scheme of loading of the samples (for the particular case of $1.5 \mathrm{~d}$ systems). The error bars of the stress correspond to the range due to scatter in the determined areas of the samples and the uncertainty of the applied force. Each loading/unloading lasted about 5-10 s. 
Accepted version. Published as: Wyrzykowski et al., Basic creep of cement paste at early age - the role of cement hydration. Cem Concr Res (2019) 116: 191-201

https://doi.org/10.1016/j.cemconres.2018.11.013

All the samples were sealed with adhesive aluminum foil. Additionally, deformations of sealed and nonloaded samples were measured as a reference to estimate the contribution of autogenous or drying shrinkage to the total measured deformation (one sample per system). The masses of the samples were determined before and after the creep tests.

The scatter presented in the specific creep results (Fig. 9 and 10) corresponds to the range of the specific creep referenced to the start of the loading cycle measured on duplicate samples. In most cases it was lower than for the two measuring gauges on the opposite sides of one sample. The latter was 11 $\mu \mathrm{m} / \mathrm{m} / \mathrm{MPa}$ at most and was typically below $3 \mu \mathrm{m} / \mathrm{m} / \mathrm{MPa}$.

When strains are presented (Fig. 7 and 8), scatter corresponds to the range of the creep or shrinkage strains referenced to the start of the experiment.

In the case in which only one sample was measured (for the $7 \mathrm{~d}$ real system and for the non-loaded reference samples), the scatter corresponds to the range of the opposite sides of the sample.

The scatter within one sample was most likely due to eccentric position of the samples and the nonuniform thickness of the walls of the cylindrical samples, resulting in non-uniform stress distribution in the sections. Moreover, close to the loading plates the stress state may have diverged from uniaxial compression. Nevertheless, the average strains calculated for each sample were relatively close between duplicate samples (see error bars).

In addition to the manual measurements described above, automatic measurements with LVDTs were carried out on part of the samples to follow the short-term creep evolution. The LVDTs were attached to the loading plates. In this way, the deformations of the samples were measured by following the displacement of the plates (assuming negligible deformations of the loading plates themselves). Three LVDTs per sample were placed at equal arc spacing around the sample. The deformations were measured on single samples and the presented data shows the average and the range from the three LVDTs measuring one sample each. The measurement time interval was $6 \mathrm{~s}$ during the first hour after loading and 10 minutes afterwards. 
Accepted version. Published as: Wyrzykowski et al., Basic creep of cement paste at early age - the role of cement hydration. Cem Concr Res (2019) 116: 191-201

https://doi.org/10.1016/j.cemconres.2018.11.013

\section{Results}

\subsection{Design and properties of the equivalent systems}

The compressive strength and elastic Young's modulus of both the equivalent and the real systems are shown in Fig. 6. It was found that the mechanical properties of the equivalent system designed to correspond to the age of $1 \mathrm{~d}$ are considerably higher than those of the real system at $1 \mathrm{~d}$. In other words, the age of the equivalent system that was initially designed to correspond to $1 \mathrm{~d}$ was underestimated. In fact, this equivalent system had mechanical properties close to those measured on the real system at the age of $1.5 \mathrm{~d}$. This is also in line with isothermal calorimetry results (Fig. 3), which show that the SEMBSE estimated hydration degree corresponds to that found with calorimetry at about $1.4 \mathrm{~d}$. Therefore, in the creep tests this equivalent system was assumed as corresponding to a real system at $1.5 \mathrm{~d}$ instead of the originally-planned $1 \mathrm{~d}$. The underestimation of the age of the youngest equivalent system was likely due to the fact that the solvent exchange method could not stop the hydration process in the real system immediately, see also [24]. Due to the high hydration rate around that time, some further hydration likely took place after immersing the samples in isopropanol at $1 \mathrm{~d}$. Another reason could be due to not resolving the smallest cement grains in the micrographs. Hence, the amount of unhydrated cement observed on SEM-BSE was lower than expected and corresponded to an age older than $1 \mathrm{~d}$.

At the same time, for the systems at $3 d$ and $7 d$ the design based on the amount of unhydrated cement in samples with arrested hydration was very close to the isothermal calorimetry estimations and allowed to obtain mechanical properties of the equivalent system very close to those of the real systems. Slightly lower compressive strength of the real systems was systematically measured, see Fig. 6a.

For the Young's modulus, Fig. $6 \mathrm{~b}$, a difference was observed at $1.5 \mathrm{~d}(8.9 \pm 0.1 \mathrm{GPa}$ and $10.2 \pm 0.3 \mathrm{GPa}$ for real and equivalent, respectively), while at 3 and $7 \mathrm{~d}$ the differences were statistically insignificant. Similar 
Accepted version. Published as: Wyrzykowski et al., Basic creep of cement paste at early age - the role of cement hydration. Cem Concr Res (2019) 116: 191-201

https://doi.org/10.1016/j.cemconres.2018.11.013

small differences in mechanical properties between the equivalent and the real systems were also reported in [30]. In any case, it should be noted that the equivalent systems do not need to exactly correspond to a chosen age of the real systems, but they should rather provide a sufficiently close representation of the microstructure (in terms of volume of hydrates, unhydrated grains and porosity) that does not hydrate further while under load.

Having obtained real and equivalent systems with very close Young's modulus was a starting point for addressing the possible differences in creep behavior; this question is studied in the following section.
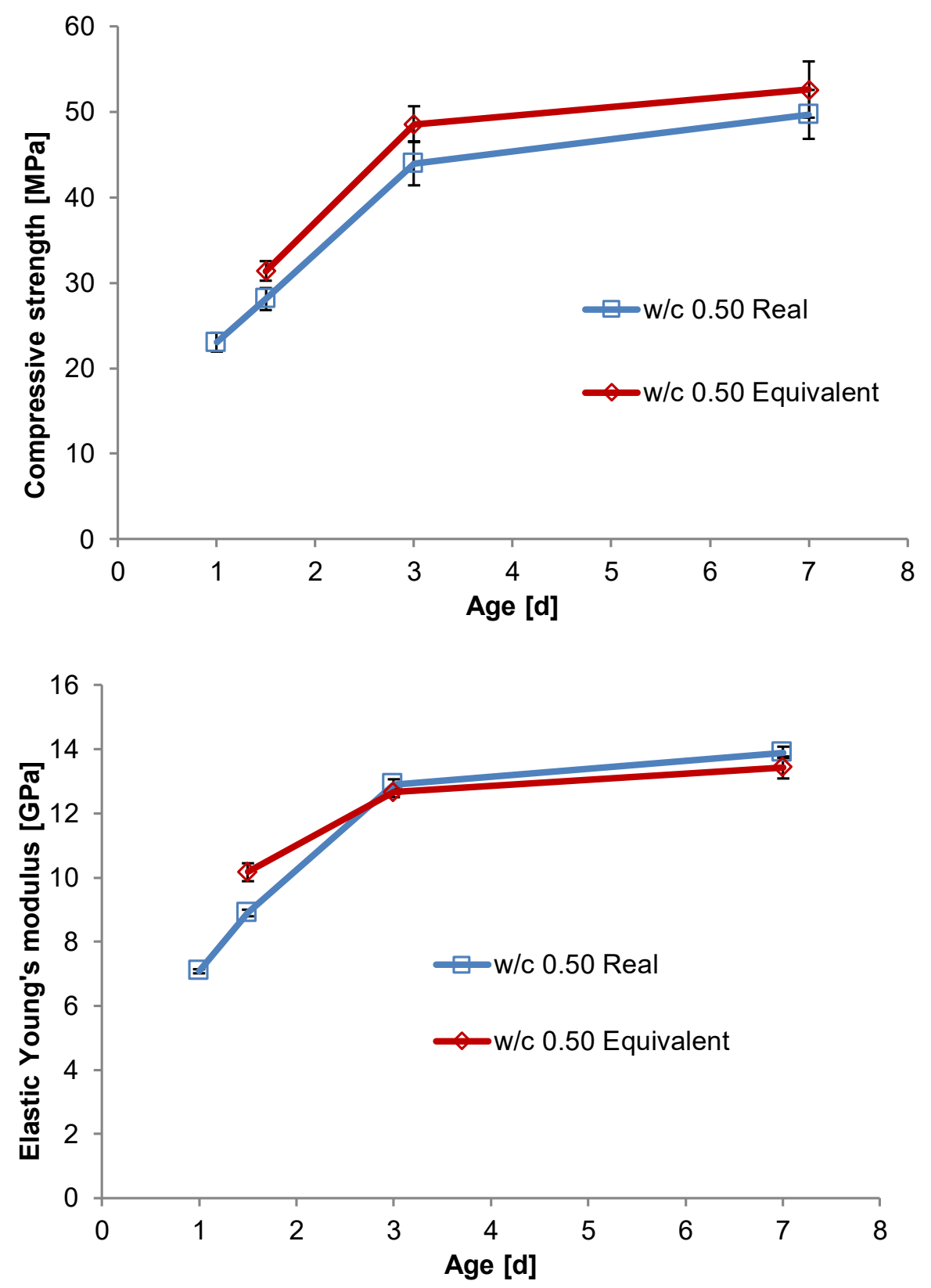
Accepted version. Published as: Wyrzykowski et al., Basic creep of cement paste at early age - the role of cement hydration. Cem Concr Res (2019) 116: 191-201

https://doi.org/10.1016/j.cemconres.2018.11.013

Fig. 6. Evolution of a) compressive strength and b) elastic Young's modulus in the real systems and in the corresponding equivalent systems.

\subsection{Creep tests}

\section{Contribution of elastic deformation and shrinkage to total measured strains}

The creep and shrinkage strains were first obtained by subtracting from the total measured strains the quasi-instantaneous (elastic) strains occurring during loading/unloading of the samples. The latter were assessed from the difference in length measured immediately before and $5 \mathrm{~min}$ after applying the load. Next, from the creep and shrinkage curves obtained in this way (full markers in Fig. 7) the shrinkage strains needed to be subtracted. The latter data was obtained on the companion non-loaded samples and is also presented in Fig. 7 (empty markers). Note that for the non-loaded samples of the real $7 \mathrm{~d}$ system, expansion was actually observed.

The shrinkage data was fitted with curves (dashed lines in Fig. 7) for the subtraction from total strains to further provide basic creep data presented in the following paragraphs. 
Accepted version. Published as: Wyrzykowski et al., Basic creep of cement paste at early age - the role of cement hydration. Cem Concr Res (2019) 116: 191-201

https://doi.org/10.1016/j.cemconres.2018.11.013
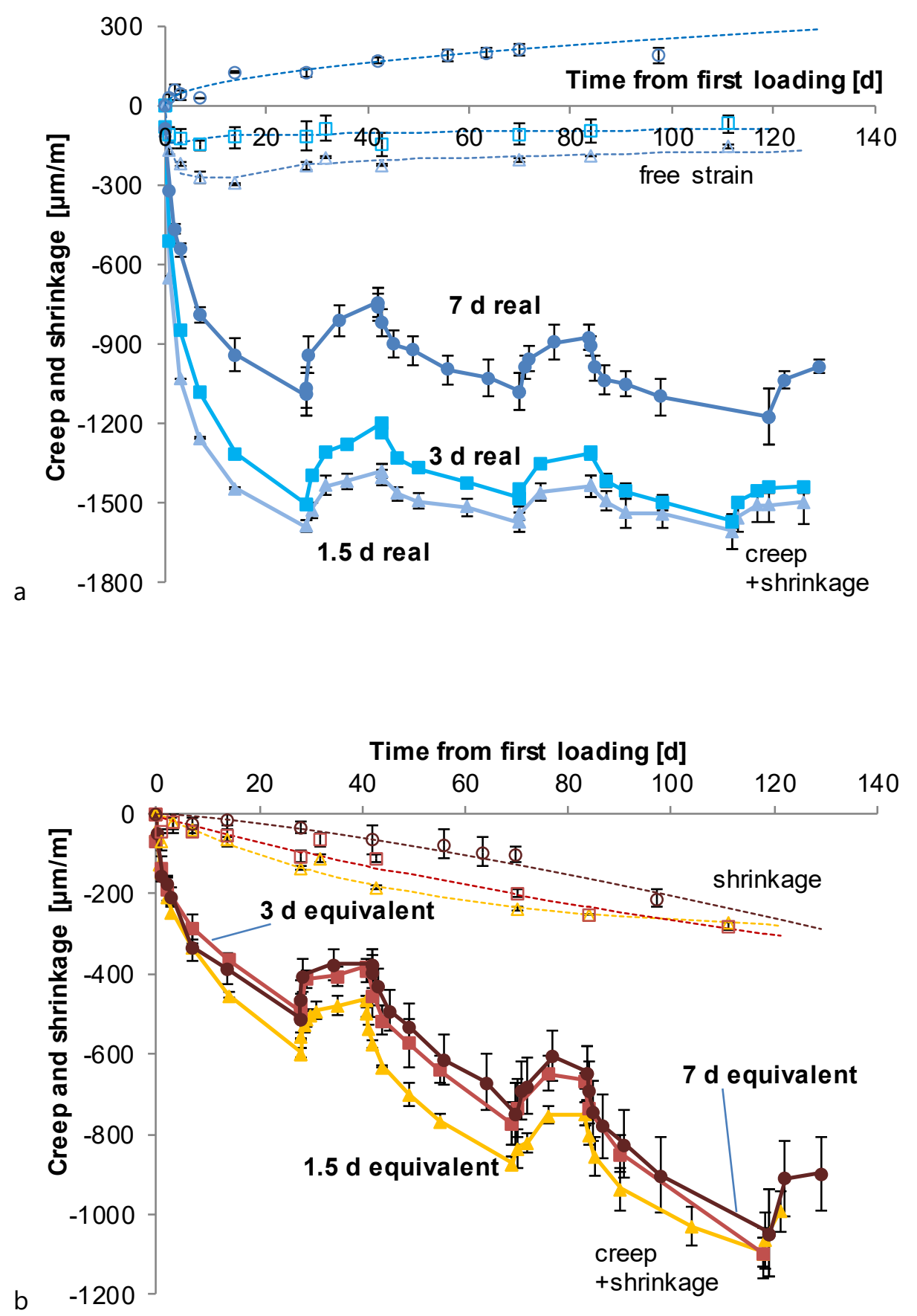

Fig. 7. Strains due to shrinkage and creep measured on the loaded samples (full markers with continuous lines, obtained after subtracting instantaneous strains at loading/unloading from the total strains) and on the companion non-loaded samples (corresponding empty symbol with fitted curvesdashed lines): a) real systems, b) equivalent systems. Loading cycles of $28 \mathrm{~d}$ (increasing creep) were followed by unloading cycles of $14 \mathrm{~d}$ (creep recovery), see Fig. 5 . 
Accepted version. Published as: Wyrzykowski et al., Basic creep of cement paste at early age - the role of cement hydration. Cem Concr Res (2019) 116: 191-201

https://doi.org/10.1016/j.cemconres.2018.11.013

It should be noted that the creep results obtained from the time instant of $5 \mathrm{~min}$ after loading/unloading necessarily miss the very short-term creep occurring rapidly after the start of loading/unloading. In order to provide better insight into the very short-term creep, the data obtained with LVDTs is presented for the $1.5 \mathrm{~d}$ systems in Fig. 8. These results were obtained starting from 12 seconds after loading.

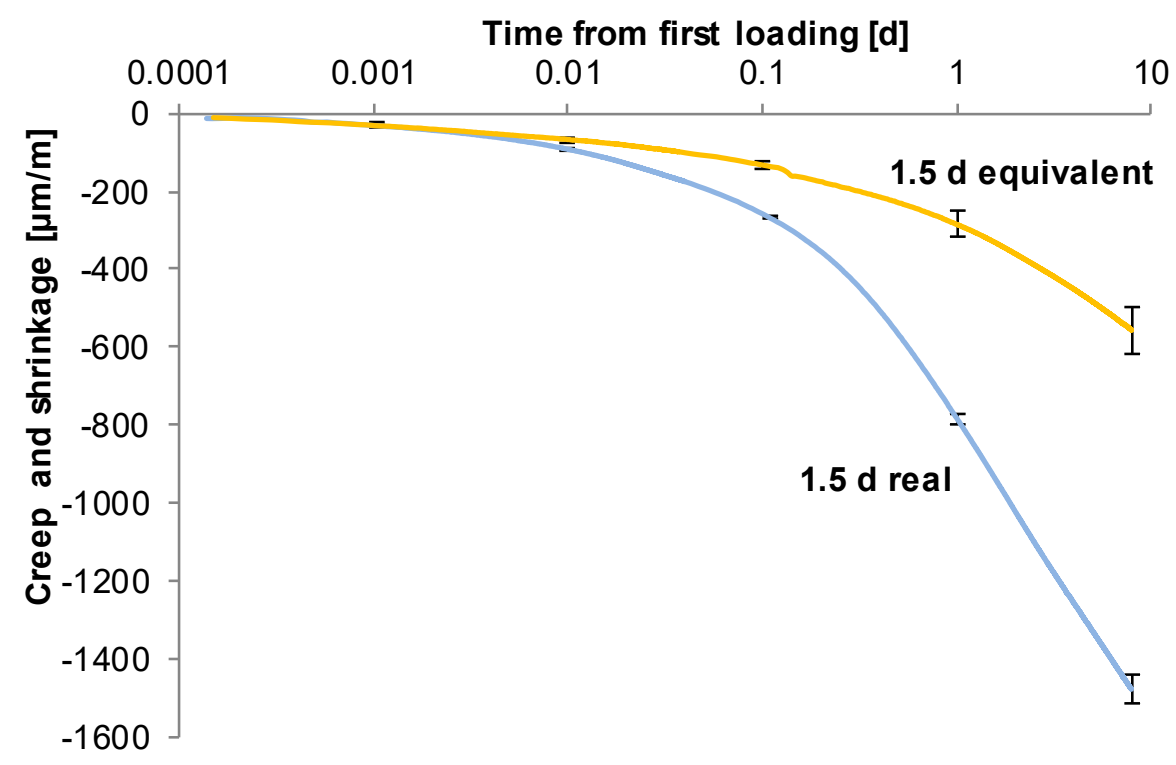

Fig. 8. Strains due to shrinkage and creep measured with LVDTs. Strains are referenced to the length at $12 \mathrm{~s}$ after loading.

\section{Specific basic creep results}

The basic creep results are presented here as specific creep (creep compliance) expressed in $[\mu \mathrm{m} / \mathrm{m} / \mathrm{MPa}]$, obtained by normalizing the basic creep (obtained by subtracting the shrinkage and instantaneous deformations as discussed in the previous paragraph) with the applied stresses. The results are presented in Fig. 9, which shows the comparison of the real systems at different loading ages and the corresponding equivalent systems during the first loading and unloading cycle. The second and third loading cycles are presented separately in Fig. 10. 
Accepted version. Published as: Wyrzykowski et al., Basic creep of cement paste at early age - the role of cement hydration. Cem Concr Res (2019) 116: 191-201

https://doi.org/10.1016/j.cemconres.2018.11.013

The differences between the corresponding real and equivalent systems become evident in particular during the first loading and unloading cycle for all analyzed ages, see Fig. 9. The real systems experience considerably higher creep strains during the first loading cycle. During subsequent loading cycles, Fig. 10 , when the real systems were considerably older, the creep strains were very similar (for 3 and $7 \mathrm{~d}$ systems) or slightly lower (for $1.5 \mathrm{~d}$ ) than in the corresponding equivalent systems.
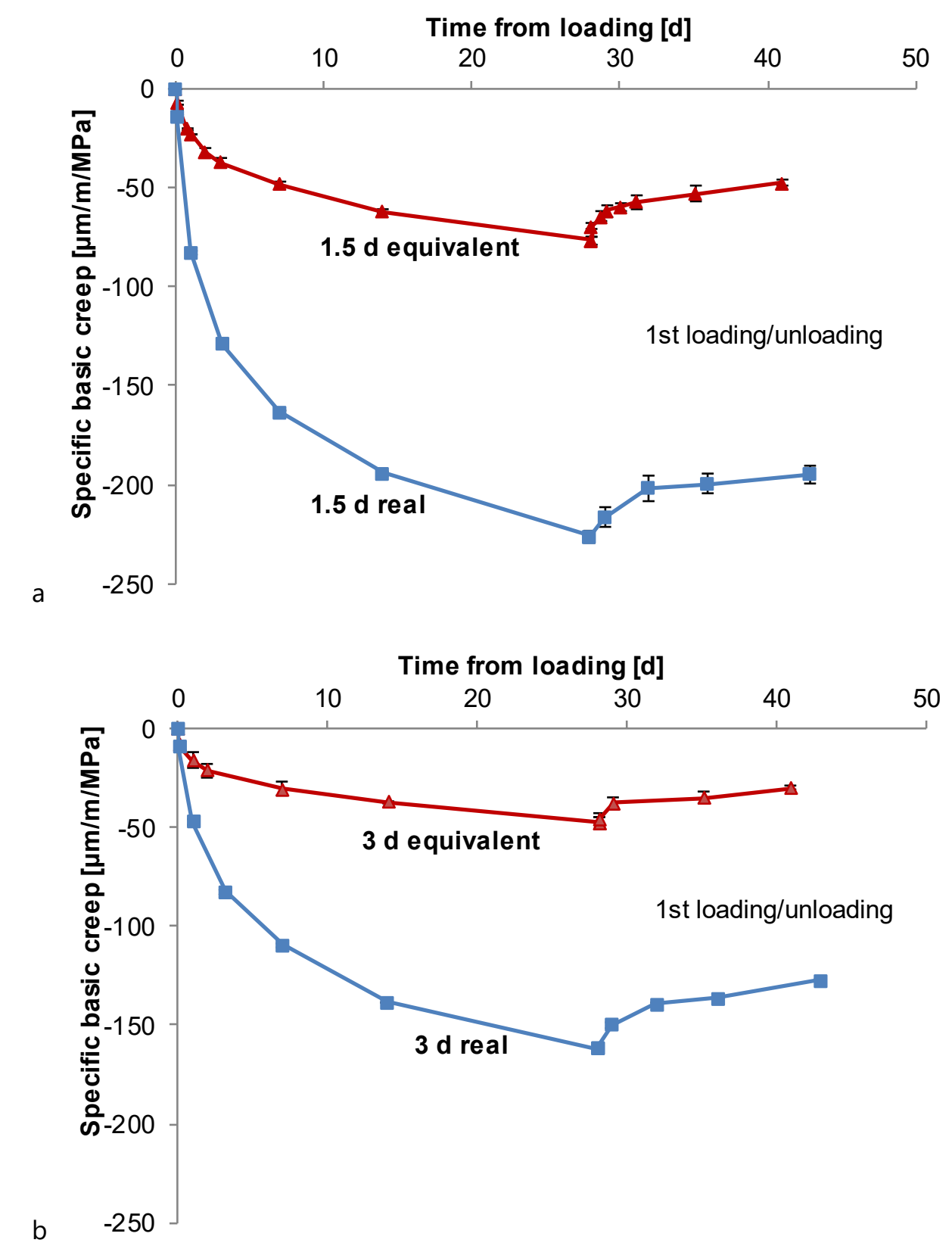
Accepted version. Published as: Wyrzykowski et al., Basic creep of cement paste at early age - the role of cement hydration. Cem Concr Res (2019) 116: 191-201

https://doi.org/10.1016/j.cemconres.2018.11.013

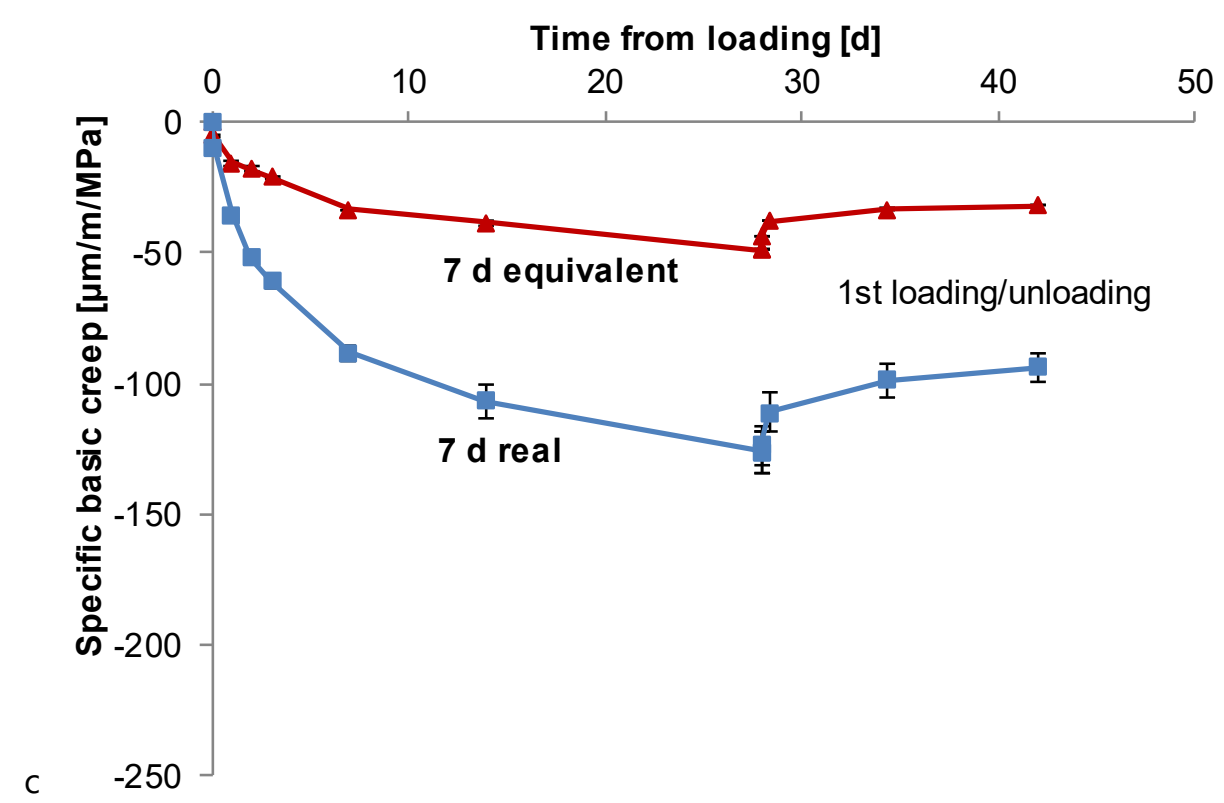

Fig. 9. Specific basic creep in compression for the real systems loaded at a) $1.5 d$, b) $3 d$ and c) $7 d$, and for the equivalent systems with hydration degrees corresponding to the ages of the real systems, respectively. The first loading and unloading cycle is presented. Creep strains were obtained after subtracting the instantaneous strains upon loading/unloading and the shrinkage strains measured on non-loaded samples (see Fig. 7).

High irreversible creep in the real systems during the first unloading cycle was most likely due to the ongoing hydration and changes in the microstructure, while higher recovery was observed in the subsequent loading cycles. However, significant irreversible creep was observed also in the equivalent systems despite the fact that these systems should not experience any microstructural evolution due to hydration and should therefore experience higher recovery of creep. 
Accepted version. Published as: Wyrzykowski et al., Basic creep of cement paste at early age - the role of cement hydration. Cem Concr Res (2019) 116: 191-201

https://doi.org/10.1016/j.cemconres.2018.11.013
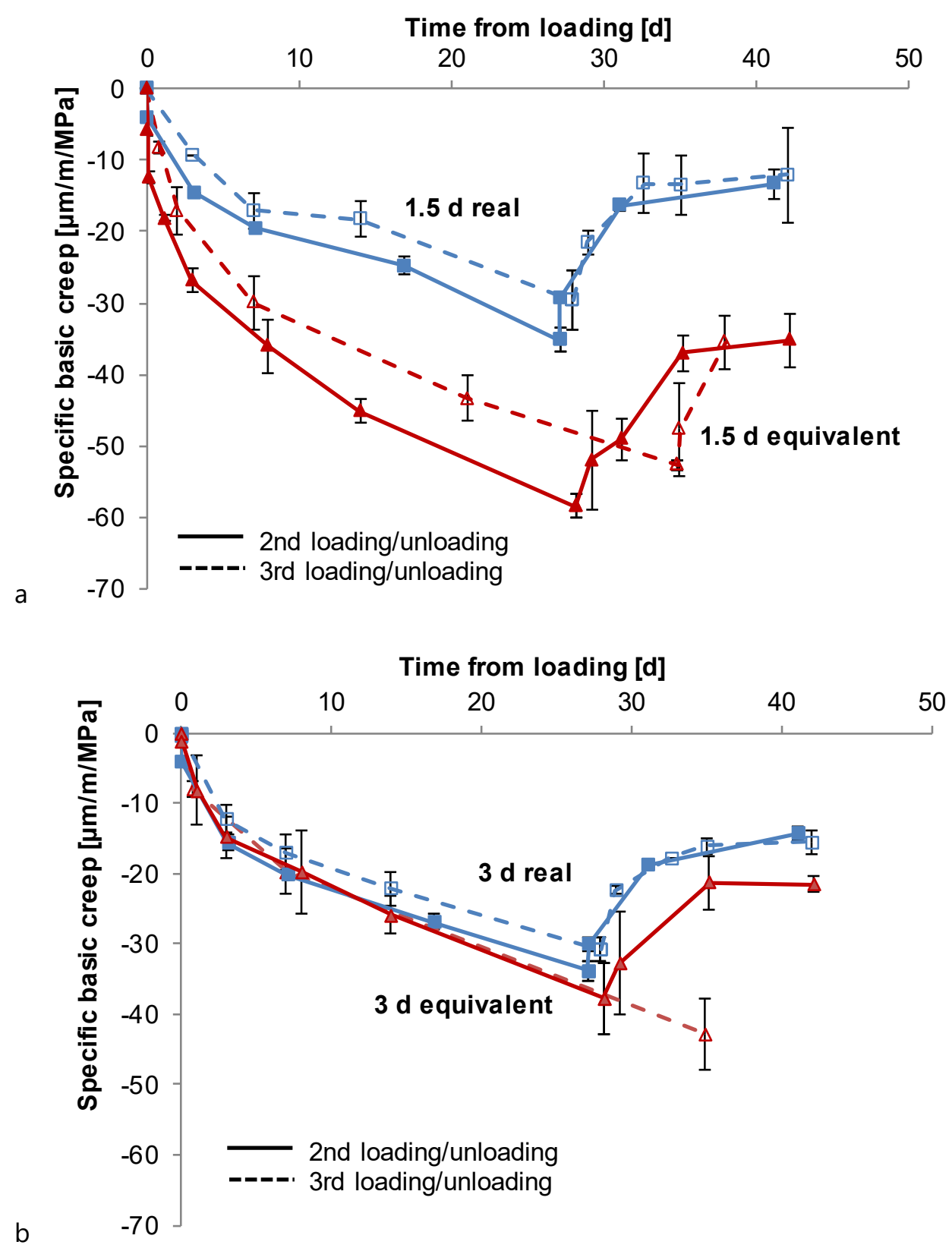
Accepted version. Published as: Wyrzykowski et al., Basic creep of cement paste at early age - the role of cement hydration. Cem Concr Res (2019) 116: 191-201

https://doi.org/10.1016/j.cemconres.2018.11.013

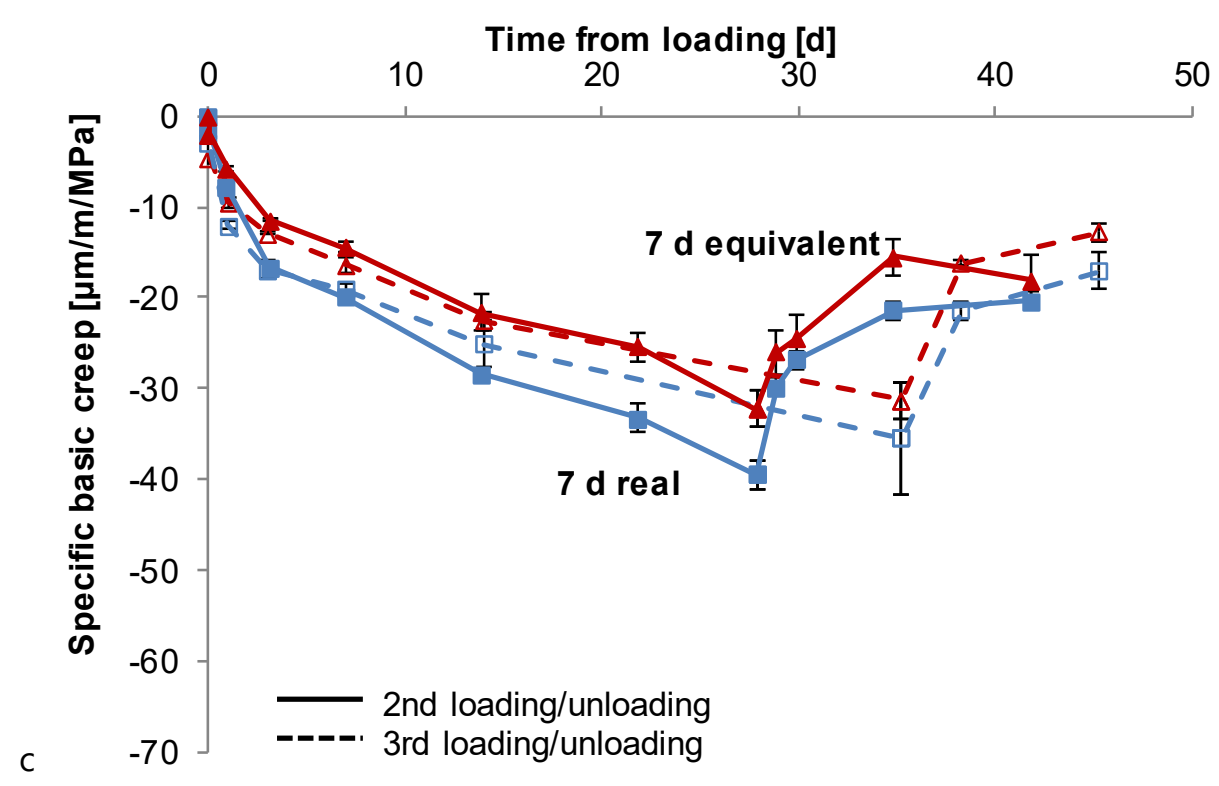

Fig. 10. Specific basic creep in compression results - same samples/measurements as in Fig. 9 but for the second and third loading cycles.

\section{Discussion}

\section{Shrinkage as a part of total measured strain}

Even though the samples were carefully sealed and a rather high w/c of 0.50 was used to limit drying and autogenous shrinkage, respectively, the measured shrinkage was nevertheless not negligible.

Autogenous shrinkage could be clearly observed on the non-loaded samples of the real systems (in particular when measured from $1.5 \mathrm{~d}$ it reached about $300 \mu \mathrm{m} / \mathrm{m}$ ) during the first 2 weeks of hydration, followed by a moderate expansion, see Fig. 7a. The supposition that the deformation was due to autogenous and not drying shrinkage is supported by negligible mass loss during the first $3 \mathrm{~d}$ of the test (when most of the shrinkage was measured), below $0.004 \%$ of sample mass. To further confirm the contribution of the autogenous shrinkage to the total deformations, autogenous shrinkage measurements with the corrugated tube protocol were carried out on triplicate samples (for details on the protocol see [36]). The shrinkage occurring between $1.5 \mathrm{~d}$ and $7 \mathrm{~d}$ reached $251 \pm 42 \mu \mathrm{m} / \mathrm{m}$ (the complete results are not presented here). The measured autogenous shrinkage is still considerably lower than observed in cement pastes at lower w/c, e.g. above $800 \mu \mathrm{m} / \mathrm{m}$ at $28 \mathrm{~d}$ was reported in [36] for 
Accepted version. Published as: Wyrzykowski et al., Basic creep of cement paste at early age - the role of cement hydration. Cem Concr Res (2019) 116: 191-201

https://doi.org/10.1016/j.cemconres.2018.11.013

pastes at $w / c 0.30$. It should be noted that using higher $w / c$ than 0.50 to further minimize the effect of autogenous shrinkage could lead to bleeding and segregation of the pastes and hence non-uniform material properties in the specimens. Therefore, a w/c of 0.50 had been chosen here as a tradeoff between autogenous shrinkage and possible instability of the mixture.

The reasons of the expansion observed at later ages (in particular initial expansion of the real $7 \mathrm{~d}$ system) are not clear, it should be however noted that the major part of the strains in the non-loaded samples occurred in the first few days of the measurements and they were considerably lower than the total strain of the loaded samples.

At the same time, for the equivalent systems, a gradual increase of shrinkage was observed on the nonloaded samples over the whole experimental period, see Fig. 7b. This was most likely due to loss of moisture through the imperfect sealing. The mass of all loaded samples was measured before and after the tests. The mass loss was below $1 \%$, or $1.8 \%$ for one real system loaded at $1.5 \mathrm{~d}$ (the total strains were however not significantly different from the companion sample with lower mass loss).

\section{General considerations on basic creep data}

The results of the real systems loaded at different ages seem to be in line with the commonly-reported results in that the creep response decreases with the age at loading, e.g. [16, 23, 37-39]. As for the magnitude of the specific creep of the real systems, very little data on plain cement pastes at a similar $\mathrm{w} / \mathrm{c}$ loaded at early age could be found in the literature. In $[16,39]$, the specific creep of $w / c 0.50$ cement pastes loaded at 1-7 d and for different lengths of load durations ( $3 \mathrm{~d}$ or $28 \mathrm{~d}$ ) was in general about 2 times larger than the corresponding results reported here. It should be however noted that in both references $[16,39]$, the presence of shrinkage strains was neglected. Moreover, the different (lower) creep magnitude observed here may have been due to the use of white Portland cement instead of ordinary gray cement. Our creep results for the real systems, even though lower than reported in [16, 
Accepted version. Published as: Wyrzykowski et al., Basic creep of cement paste at early age - the role of cement hydration. Cem Concr Res (2019) 116: 191-201

https://doi.org/10.1016/j.cemconres.2018.11.013

39] are in any case considerably higher than those for the equivalent systems; this difference is the major topic of the further discussion.

The creep of the equivalent systems appears to be, as expected, to a large extent non-aging, i.e. the rate of creep changes much less than for the real systems at early age and the creep during subsequent loading cycles is similar to that at the $1^{\text {st }}$ loading cycle, especially for the $3 d$ and $7 d$ systems, se Fig. 9 and 10. On the contrary, for the real systems, a clear change in the creep rate occurs during the first cycle, while the second and the third loading cycles are similar, showing negligible aging at later ages.

The results in Fig. 9 invariably show that the equivalent systems are not suitable as model systems for emulating creep at early ages. Even though the real and equivalent systems are designed to have similar volumes of hydrates and porosity (see [30]) and indeed do have similar elastic Young's moduli (see Fig. $6 b)$, the creep response of the real systems is significantly higher than that of the corresponding equivalent systems during the first $28 \mathrm{~d}$ after first loading. The differences between the equivalent systems become lower with progressing hydration. The differences are of course most prominent during the first loading cycle. Later, the real systems have significantly higher mechanical properties and lower creep and do not correspond to any equivalent systems any more.

The difference in creep between the real and the equivalent systems becomes even more evident if one considers that the real systems are undergoing continuous hydration at high rates in the first days to weeks after first loading. This leads to a considerable development of microstructure and causes significant reduction of creep rate over hydration time. In fact, the volume of the hydration products at any time after loading should be higher in the real systems than in the corresponding equivalent systems. Yet, the creep response is not only not lower, but is still considerably higher in the real systems than in the equivalent systems, even in the most extreme case studied here: the real system loaded at $7 \mathrm{~d}$ experiences more creep than the equivalent $1.5 \mathrm{~d}$ system, despite the former having approximately $50 \%$ higher volume of hydrated cement and significantly higher mechanical properties than the latter.

The experimental results obtained on the equivalent systems here and in previous publications $[30,33]$ lead us to conclude that the volumes of different phases in a microstructure are a factor that, to a first 
Accepted version. Published as: Wyrzykowski et al., Basic creep of cement paste at early age - the role of cement hydration. Cem Concr Res (2019) 116: 191-201

https://doi.org/10.1016/j.cemconres.2018.11.013

approximation, in major part dictates the elastic and strength properties (this feature also enables estimating elastic properties based on volume fractions with composite models, e.g. [40]). This is in line with the common observation that evolution (hardening) of the elastic and strength properties after the percolation of solids is primarily driven by solidification of load-bearing components due to hydration [41-43]. On the contrary, there is no such correspondence with regard to aging of creep: invariably in this study, two pastes with similar volumetric compositions, one with ongoing and one with arrested hydration, experienced considerably different creep responses. Three hypotheses could explain this difference: 1) assuming that the morphology of the hydration products and their spatial arrangements are significantly different between the real and equivalent systems, these differences play a significant role in the creep response, 2) intrinsic aging of hydration products takes place and/or 3) the ongoing hydration process itself leads to higher creep. These results are further discussed in the frame of recent and most prominent theories of creep of cement paste.

\section{Solidification and microprestress-solidification theories}

In one of the most prominent theories of aging creep, the solidification theory of concrete creep [10], Bažant and Prasannan suggested that "the aging aspect of creep is due to growing of volume fraction of the load-bearing solidified matter (i.e. hydrated cement), the properties of which are ageindependent". The hydrates themselves are intrinsically viscoelastic. Further, according to this theory the newly-formed hydration products are initially stress-free and become loaded only after their formation. In practical terms, aging is described as the effect of stress being simply normalized by a solidification factor, the latter being a proxy of the volume of the solidified load-bearing hydration products.

One additional argument that Bažant and Prasannan [10] put forward (to explain the age-dependence of creep, even for very old concrete) is the formation of new bonds (similar to polymerization) even in fully-hydrated cement. Polymerization of silicates leading to bridging of colloid particles to form a more organized gel structure was postulated also by Jennings [44] as the main mechanism responsible for aging. There is further experimental evidence on forming higher polymeric species (longer silicate 
Accepted version. Published as: Wyrzykowski et al., Basic creep of cement paste at early age - the role of cement hydration. Cem Concr Res (2019) 116: 191-201

https://doi.org/10.1016/j.cemconres.2018.11.013

chains) in C-S-H with age [45-47]. Parrot [48] reported that cement pastes of different w/c (0.23-0.71) experienced about 2 times lower creep when loaded at about 1 year compared to those loaded at $28 \mathrm{~d}$. Another mechanism explaining reduction of creep at ages when hydration and solidification are hardly active proposed by Bažant and coworkers $[6,49]$ was relaxation of microprestress. According to the microprestress-solidification theory, the solid framework carries tensile stress (microprestress) as a reaction to disjoining pressure acting in nano-sized pores (in the hindered adsorption areas). Creep occurs due to shear slip across these nanopores and the slip process is amplified by the magnitude of microprestress. During creep, breakage of bonds across the nanopores ("bridges") and their restoration leads to relaxation of shear stress and hence reduction of creep.

In any case, the long term mechanisms like polymerization or relaxation of microprestress causing aging seem unrealistic for the particular systems and time ranges studied in this paper, since creep reaches a similar magnitude in the $2^{\text {nd }}$ and $3^{\text {rd }}$ loading cycles (i.e. between 42 and $108 \mathrm{~d}$ ) for all systems, both real and equivalent, see Fig. 10.

As mentioned in the introduction, Irfan-ul-Hassan et al. [23] carried out 3-min long compressive creep tests repeated at early age at $1 \mathrm{~h}$ intervals. Taking advantage of the short duration of each loading stage, they captured the evolution of the viscoelastic properties with hydration between the 1-h loading cycles. They propose that aging is due to reduction of capillary porosity and hence lower stress concentration on the creeping hydrates, thus their description is in line with the solidification theory by Bažant and Prasannan [10].

However, Grasley and Lange [13] show, based on their experimental creep data, that aging of viscoelastic properties cannot be described solely with solidification. In fact, considering inherent aging of the hydration products in addition to solidification allows for better agreement with their data. In short, their argument is based on the fact that, as long as elasticity can be described as a function of solidification, such description evidently fails for viscoelastic properties since the latter evolve much more at early age than the former. Also, Li et al. [14] have shown with a micrometer-scale FEM modelling that it is possible 
Accepted version. Published as: Wyrzykowski et al., Basic creep of cement paste at early age - the role of cement hydration. Cem Concr Res (2019) 116: 191-201

https://doi.org/10.1016/j.cemconres.2018.11.013

to simulate apparent aging of the systems composed of elastic clinker and intrinsically viscoelastic/viscoplastic C-S-H only if intrinsic aging of the $\mathrm{C}-\mathrm{S}-\mathrm{H}$ is included in the model.

\section{Dissolution theory}

According to the model presented by Li et al. [7], the creep deformation can be described as an effect of decreasing stiffness and corresponding deformation under load when the stiff anhydrous cement dissolves and the load is transferred to the less stiff hydration products. After the dissolution, the newlyhydrated products form in a stress-free state, similarly as in the solidification theory. Such approach requires considering that the elastic clinker contributes to load bearing in addition to the hydrated phases. Upon dissolution, stress is redistributed from the dissolved phases to the hydrated phases. This means that the average stress on the hydrates increases along with hydration as load is redistributed to them from the elastic unhydrated phase that dissolves. This constitutes a major difference compared to the solidification theory of creep [10], where stress carried by the hydrates decreases with time/solidification process as the hydrates are the only component capable of bearing stress and their volume increases with time. This difference in considering the load-bearing capacity of different phases after percolation of the solid skeleton has major repercussions with regard to the predictions of stresses and creep/relaxation of a hardening composite.

The dissolution model enables the description of the apparent aging viscoelasticity even in the absence of any intrinsically-viscoelastic components. Dissolution theory explains aging of creep as an effect of the decreasing hydration and dissolution rates with age. One important feature of the dissolution theory of creep is that this mechanism can only be active while hydration is ongoing, i.e. where there are clinker grains that can dissolve causing corresponding strain. Li et al. thus further analyzed in [14] different, arbitrarily assumed forms of aging functions and concluded that at early ages (below about $3 \mathrm{~d}$ ) the dissolution mechanism should play a major role, while later, when the rate of hydration is much lower, intrinsic aging should be dominant. 
Accepted version. Published as: Wyrzykowski et al., Basic creep of cement paste at early age - the role of cement hydration. Cem Concr Res (2019) 116: 191-201

https://doi.org/10.1016/j.cemconres.2018.11.013

According to the dissolution theory, partial creep recovery would take place because after unloading the new hydrated phases formed during the loading stage restrain partially the recovery of deformation and are therefore subject to stress, leading to creep (dissolution or intrinsic) upon unloading in the direction opposite to that during loading.

Grasley et al. [50] proposed based on theoretical considerations that the stress-induced dissolution of hydrated phases could further contribute to the apparent creep in hydrated systems; this approach was also supported by the simuations by Li et al. [51] . Also, Pignatelli et al. [8], based on some experimental evidence argued that dissolution of $\mathrm{C}-\mathrm{S}-\mathrm{H}$ due to applied stress could contribute to creep. We find this mechanism of negligible importance at early age, where the dissolution of cement and precipitation of hydrates due to ongoing hydration is by magnitudes larger than due to applied stress, and hence the effect on creep of the latter should be minor in the real systems.

\section{Interpretation of the results of the equivalent systems}

The fact that systems with higher volumes of hydrates can experience higher creep than systems with lower volumes of hydrates, and that the equivalent systems with different volumes of hydrates (equivalent to $3 \mathrm{~d}$ and $7 \mathrm{~d}$ systems) but having really the same age (over $90 \mathrm{~d}$ ) experience similar creep (compare Fig. 8b and 8c), cannot be explained with the solidification theory of creep. Our results also appear to be in contrast with the observation by Irfan-ul-Hassan et al. [23], who show that the creep response is to a certain level of approximation a universal function of the gel/space ratio for the range of different w/c cement pastes analyzed in their work.

One possible explanation of the observed differences between the real and the equivalent systems could be that the hydrates (mainly $\mathrm{C}-\mathrm{S}-\mathrm{H}$ ) in those systems, despite occupying similar volumes, have considerably different properties/morphologies, resulting in completely different intrinsic viscoelastic properties. There can be two major reasons for the possible differences in creep behavior:

- Age/hydration: equivalent systems are hydrating for over $90 \mathrm{~d}$ before the first loading, while real systems are loaded during the first week of hydration. Muller et al. [52] have shown that 
Accepted version. Published as: Wyrzykowski et al., Basic creep of cement paste at early age - the role of cement hydration. Cem Concr Res (2019) 116: 191-201

https://doi.org/10.1016/j.cemconres.2018.11.013

densification of $\mathrm{C}-\mathrm{S}-\mathrm{H}$ (excluding gel water) is negligible after the first stages of hydration, and the densification of the $\mathrm{C}-\mathrm{S}-\mathrm{H}$ gel (at the expense of the gel porosity) occurs only after the interhydrate spaces are filled with the gel (in a w/c 0.40 paste it occurred around 2 months as reported in [52]). This is however very unlikely to happen at later ages in the equivalent systems tested here, considering their high $\mathrm{w} / \mathrm{c}$ and therefore high volume of available interhydrate/capillary porosity (see Table 1). Another mechanism that could explain intrinsic aging of the C-S-H could be silicate polymerization [44-47] leading to a higher level of organization of the $\mathrm{C}-\mathrm{S}-\mathrm{H}$ and hence higher stiffness. The stiffer $\mathrm{C}-\mathrm{S}-\mathrm{H}$ in the equivalent systems could also explain why the equivalent systems have similar elastic properties as the real systems, despite the fact that quartz used in equivalent systems is considerably less stiff (about $60 \mathrm{GPa}$ [53]) than the clinker (about $140 \mathrm{GPa}[53,54])$ in the real systems. This may be in fact the fundamental reason behind the applicability of the equivalent systems in emulating elastic properties of the real systems. In any case, any increase of the stiffness of the C-S-H (due to polymerization or any other process) should take place around 1-1.5 months of age, as at later ages no significant evolution of creep properties (aging) took place in the real systems. This is evidenced by similar creep results in the second and third loading/unloading cycles, see Fig. 10.

- Presence of filler replacing clinker: one could expect that the clinker grains in the real systems and the quartz grains (in absence of virtually any clinker) in the equivalent systems correspond to different spatial distributions of the densities of the hydrates (C-S-H). We suggest that there could be denser $\mathrm{C}-\mathrm{S}-\mathrm{H}$ (so-called inner $\mathrm{C}-\mathrm{S}-\mathrm{H}$ ) in the direct vicinity of clinker grains in the real systems, see e.g. $[55,56]$, while less stiff products are present far away from them. On the contrary, in the equivalent systems the quartz inclusions could be in contact with the less dense $\mathrm{C}-\mathrm{S}-\mathrm{H}$, whereas denser $\mathrm{C}-\mathrm{S}-\mathrm{H}$ would be primarily present away from the quartz fillers (where the original, now fully hydrated, clinker was initially present).

The latter argument suggests that the observed different creep behaviors may be rather due to different microstructural arrangements at a scale level higher than the level of the $\mathrm{C}-\mathrm{S}-\mathrm{H}$ itself, and hence originate 
Accepted version. Published as: Wyrzykowski et al., Basic creep of cement paste at early age - the role of cement hydration. Cem Concr Res (2019) 116: 191-201

https://doi.org/10.1016/j.cemconres.2018.11.013

from the sliding processes between the hydrates (not necessarily C-S-H). These probable differences in morphologies of the $\mathrm{C}-\mathrm{S}-\mathrm{H}$ are at this stage purely speculative and indicate the topics of the further research. Specifically, it is not clear, without involving microstructural modelling, why these two possible different spatial arrangements of the densities of the $\mathrm{C}-\mathrm{S}-\mathrm{H}$ would lead to such prominent differences in creep.

The fact that the equivalent systems show higher creep during the first loading cycles and slightly lower creep during the second and third loading cycles shows that the microstructure is reorganized on loading in a way that affects its creep behavior, while it affects less the elastic behavior. Such behavior could be explained by sliding of the hydrates (here mainly stacks of sheets or needles of C-S-H) towards a jammed state, causing some degree of densification of the hydrates and leading consequently to less creep (but not affecting the elastic properties considerably), as suggested based on nanoindentation tests by Vandamme and Ulm [5] and being in line with the microprestress theory of creep [6].

Another mechanism that could to a certain extent explain the observed results stems from the dissolution theory of creep [7]. According to this theory, the real systems at early age would experience much more creep than the equivalent systems because they are at a relatively early stage of hydration and thus contain a high volume of anhydrous clinker that can dissolve leading to corresponding deformation (creep). On the contrary, in the equivalent systems the clinker is replaced by inert quartz and hence there is very little dissolution possible as there is virtually no anhydrous clinker left. However, the fact that the equivalent systems where the hydration-related dissolution is not active still show nonnegligible creep (the same holds for the creep response of the very old, fully hydrated systems) cannot be explained with the hydration-induced dissolution theory and hence confirms that at least part of the measured creep is due to the intrinsic viscoelastic properties of the cement-paste, which is also in line with findings of indentation studies $[4,5,22]$. Another hypothesis that could explain at least part of the creep visible in the equivalent systems and real systems at later ages stems from the stress-induced dissolution of hydrates, as postulated in $[8,50,51]$. 
Accepted version. Published as: Wyrzykowski et al., Basic creep of cement paste at early age - the role of cement hydration. Cem Concr Res (2019) 116: 191-201

https://doi.org/10.1016/j.cemconres.2018.11.013

\section{Conclusions}

We performed compressive creep measurements on w/c 0.50 cement pastes at early ages (first loading at $1.5 \mathrm{~d}, 3 \mathrm{~d}$ and $7 \mathrm{~d}$ ). Basic creep strains were obtained by subtracting the quasi-instantaneous strain occurring on loading and the strains measured on the companion non-loaded samples.

The basic creep in compression of these systems, referred to as the real systems, was compared to the creep measured on the corresponding equivalent systems. Equivalent systems are pastes in which part of the cement was replaced with fine quartz powder. This quartz emulates anhydrous cement present in a real system at the corresponding (equivalent) age, while the volume of water and solids remain the same. After a long time of hydration ( $>90 \mathrm{~d}$ ), equivalent systems are obtained that are inert and have similar volumes of hydrates and porosity as the corresponding real systems at early age. Even though the strength and elastic Young's moduli are similar between the real and the equivalent systems, completely different creep behavior was observed. The real systems loaded at early age showed considerably higher creep than the corresponding equivalent systems.

These novel results are used to discuss different theories about fundamental mechanisms of basic creep and aging of creep. While solidification theory can explain the similar elastic and strength properties of the real and equivalent systems, it fails to explain the large differences in creep between systems that have similar volumes of hydration products. The considerably higher creep in the hydrating real systems compared to the equivalent systems can be the consequence of:

1) Different morphologies of hydrates (mainly C-S-H) in the two types of systems, supposedly denser C-S-H concentrated in the vicinity of elastic inclusions (clinker) in the real systems and far away from the elastic inclusions (quartz) in the equivalent systems. If this hypothesis were valid, it would further impose that creep originates in large part from a sliding process at the scale of hydrates (not necessarily C-S-H) and not within the hydrates. Further studies are necessary to investigate to which extent such possible different microstructural arrangements could affect creep; 
Accepted version. Published as: Wyrzykowski et al., Basic creep of cement paste at early age - the role of cement hydration. Cem Concr Res (2019) 116: 191-201

https://doi.org/10.1016/j.cemconres.2018.11.013

2) Inherent aging of the viscoelastic properties of hydrates (mainly C-S-H). Since the equivalent systems are invariably older than the corresponding real systems, if inherent aging of $\mathrm{C}-\mathrm{S}-\mathrm{H}$ was active (e.g. due to polymerization of the silicates or relaxation of microprestress), the former should experience less creep;

3) The role of hydration in creep. This is partially in line with the dissolution theory of creep that has been proposed recently. The real systems, which experience undergoing hydration and hence dissolution of clinker, show larger apparent creep due to redistribution of stresses from stiffer clinker to less stiff hydration products.

\section{Acknowledgements}

Research presented in this paper was supported by the Swiss National Science Foundation (SNSF) within the framework of the Ambizione grant of Mateusz Wyrzykowski (project 161414, "Role of water redistribution in creep of concrete"). We would like to thank Dr. Bernhard Pichler and Prof. Christian Hellmich from TU Wien and Prof. Zachary Grasley from Texas A\&M University for valuable discussion on creep mechanisms.

\section{References}

[1] Z.P. Bažant, Prediction of concrete creep and shrinkage: past, present and future, Nuclear Engineering and Design, 203 (2001) 27-38.

[2] A.M. Neville, Creep of concrete as a function of its cement paste content, Magazine of Concrete Research, 16 (1964) 21-30.

[3] M. Vandamme, F.J. Ulm, Nanoindentation investigation of creep properties of calcium silicate hydrates, Cem Concr Res, 52 (2013) 38-52.

[4] C.A. Jones, Z.C. Grasley, Short-term creep of cement paste during nanoindentation, Cem Concr Compos, 33 (2011) 12-18.

[5] M. Vandamme, F.-J. Ulm, Nanogranular origin of concrete creep, Proceedings of the National Academy of Sciences, 106 (2009) 10552-10557.

[6] Z. Bažant, A. Hauggaard, S. Baweja, F. Ulm, Microprestress-Solidification Theory for Concrete Creep. I: Aging and Drying Effects, Journal of Engineering Mechanics, 123 (1997) 1188-1194.

[7] X. Li, Z.C. Grasley, E.J. Garboczi, J.W. Bullard, Modeling the apparent and intrinsic viscoelastic relaxation of hydrating cement paste, Cem Concr Compos, 55 (2015) 322-330. 
Accepted version. Published as: Wyrzykowski et al., Basic creep of cement paste at early age - the role of cement hydration. Cem Concr Res (2019) 116: 191-201

https://doi.org/10.1016/j.cemconres.2018.11.013

[8] I. Pignatelli, A. Kumar, R. Alizadeh, Y.L. Pape, M. Bauchy, G. Sant, A dissolution-precipitation mechanism is at the origin of concrete creep in moist environments, The Journal of Chemical Physics, 145 (2016) 054701.

[9] M. Shahidi, B. Pichler, C. Hellmich, Viscous interfaces as source for material creep: A continuum micromechanics approach, European Journal of Mechanics - A/Solids, 45 (2014) 41-58.

[10] Z.P. Bažant, S. Prasannan, Solidification theory for aging creep, Cem Concr Res, 18 (1988) 923-932.

[11] J.J. Thomas, H.M. Jennings, A colloidal interpretation of chemical aging of the C-S-H gel and its effects on the properties of cement paste, Cem Concr Res, 36 (2006) 30-38.

[12] P. Rossi, J.-L. Tailhan, F. Le Maou, L. Gaillet, E. Martin, Basic creep behavior of concretes investigation of the physical mechanisms by using acoustic emission, Cem Concr Res, 42 (2012) 61-73.

[13] Z.C. Grasley, D.A. Lange, Constitutive modeling of the aging viscoelastic properties of portland cement paste, Mech Time-Depend Mater, 11 (2007) 175-198.

[14] X. Li, Z.C. Grasley, E.J. Garboczi, J.W. Bullard, Simulation of the influence of intrinsic C-S-H aging on time-dependent relaxation of hydrating cement paste, Constr Build Mater, 157 (2017) 1024-1031.

[15] P. Lura, O.M. Jensen, K. van Breugel, Autogenous shrinkage in high-performance cement paste: An evaluation of basic mechanisms, Cem Concr Res, 33 (2003) 223-232.

[16] Z.C. Grasley, C.K. Leung, Desiccation shrinkage of cementitious materials as an aging, poroviscoelastic response, Cem Concr Res, 41 (2011) 77-89.

[17] A. Aili, M. Vandamme, J.-M. Torrenti, B. Masson, Is long-term autogenous shrinkage a creep phenomenon induced by capillary effects due to self-desiccation?, Cem Concr Res, 108 (2018) 186-200.

[18] Q. Zhang, R. Le Roy, M. Vandamme, B. Zuber, Long-term creep properties of cementitious materials: Comparing microindentation testing with macroscopic uniaxial compressive testing, Cem Concr Res, 58 (2014) 89-98.

[19] Z. Chen, L. Sorelli, J. Frech-Baronet, J. Sanahuja, M. Vandamme, J. Chen, Duality between Creep and Relaxation of a Cement Paste at Different Levels of Relative Humidity: Characterization by

Microindentation and Analytical Modeling, Journal of Nanomechanics and Micromechanics, 7 (2017) 04017017.

[20] P. Trtik, B. Münch, P. Lura, A critical examination of statistical nanoindentation on model materials and hardened cement pastes based on virtual experiments, Cem Concr Compos, 31 (2009) 705-714.

[21] P. Lura, P. Trtik, B. Münch, Validity of recent approaches for statistical nanoindentation of cement pastes, Cem Concr Compos, 33 (2011) 457-465.

[22] M. Vandamme, C.A. Tweedie, G. Constantinides, F.-J. Ulm, K.J. Van Vliet, Quantifying plasticityindependent creep compliance and relaxation of viscoelastoplastic materials under contact loading, Journal of Materials Research, 27 (2011) 302-312.

[23] M. Irfan-ul-Hassan, B. Pichler, R. Reihsner, C. Hellmich, Elastic and creep properties of young cement paste, as determined from hourly repeated minute-long quasi-static tests, Cem Concr Res, 82 (2016) 36-49.

[24] J. Zhang, G.W. Scherer, Comparison of methods for arresting hydration of cement, Cem Concr Res, 41 (2011) 1024-1036.

[25] N.C. Collier, J.H. Sharp, N.B. Milestone, J. Hill, I.H. Godfrey, The influence of water removal techniques on the composition and microstructure of hardened cement pastes, Cem Concr Res, 38 (2008) 737-744.

[26] Z.P. Bažant, J.C. Chern, Concrete creep at variable humidity: constitutive law and mechanism, Mater Struct, 18 (1985) 1-20.

[27] B.T. Tamtsia, J.J. Beaudoin, Basic creep of hardened cement paste A re-examination of the role of water, Cem Concr Res, 30 (2000) 1465-1475. 
Accepted version. Published as: Wyrzykowski et al., Basic creep of cement paste at early age - the role of cement hydration. Cem Concr Res (2019) 116: 191-201

https://doi.org/10.1016/j.cemconres.2018.11.013

[28] J. Beaudoin, B. Tamtsia, Creep of Hardened Cement Paste-The Role of Interfacial Phenomena, Interface Science, 12 (2004) 353-360.

[29] P. Termkhajornkit, R. Barbarulo, G. Chanvillard, Microstructurally-designed cement pastes: A mimic strategy to determine the relationships between microstructure and properties at any hydration degree, Cem Concr Res, 71 (2015) 66-77.

[30] C. Di Bella, M. Wyrzykowski, M. Griffa, P. Termkhajornkit, G. Chanvillard, H. Stang, A. Eberhardt, P. Lura, Application of microstructurally-designed mortars for studying early-age properties:

Microstructure and mechanical properties, Cem Concr Res, 78 (2015) 234-244.

[31] T.C. Powers, T.L. Brownyard, Studies of the physical properties of hardened Portland cement paste, Bull. 22, Res. Lab. of Portland Cement AssociationSkokie, IL, USA, 1948.

[32] C. Di Bella, A. Michel, H. Stang, P. Lura, Early age fracture properties of microstructurally-designed mortars, Cem Concr Compos, 75 (2017) 62-73.

[33] C. Di Bella, M. Griffa, T.J. Ulrich, P. Lura, Early-age elastic properties of cement-based materials as a function of decreasing moisture content, Cem Concr Res, 89 (2016) 87-96.

[34] C. Di Bella, Drying shrinkage of cementitious materials at early age, ETH Zurich, 2016.

[35] X. Pang, D.P. Bentz, C. Meyer, G.P. Funkhouser, R. Darbe, A comparison study of Portland cement hydration kinetics as measured by chemical shrinkage and isothermal calorimetry, Cem Concr Compos, 39 (2013) 23-32.

[36] M. Wyrzykowski, Z. Hu, S. Ghourchian, K. Scrivener, P. Lura, Corrugated tube protocol for autogenous shrinkage measurements: review and statistical assessment, Mater Struct, 50 (2017) 1-14.

[37] L. Østergaard, D.A. Lange, S.A. Altoubat, H. Stang, Tensile basic creep of early-age concrete under constant load, Cem Concr Res, 31 (2001) 1895-1899.

[38] B.T. Tamtsia, J.J. Beaudoin, J. Marchand, The early age short-term creep of hardening cement paste: load-induced hydration effects, Cem Concr Compos, 26 (2004) 481-489.

[39] R. Ghosh, Creep of Portland cement paste at early ages, Mat. Constr., 5 (1972) 93-97.

[40] Z. Hashin, S. Shtrikman, A variational approach to the theory of the elastic behaviour of multiphase materials, Journal of the Mechanics and Physics of Solids, 11 (1963) 127-140.

[41] A. Boumiz, C. Vernet, F.C. Tenoudji, Mechanical properties of cement pastes and mortars at early ages: Evolution with time and degree of hydration, Advanced Cement Based Materials, 3 (1996) 94106.

[42] O. Bernard, F.-J. Ulm, E. Lemarchand, A multiscale micromechanics-hydration model for the earlyage elastic properties of cement-based materials, Cem Concr Res, 33 (2003) 1293-1309.

[43] B. Pichler, C. Hellmich, J. Eberhardsteiner, J. Wasserbauer, P. Termkhajornkit, R. Barbarulo, G. Chanvillard, Effect of gel-space ratio and microstructure on strength of hydrating cementitious materials: An engineering micromechanics approach, Cem Concr Res, 45 (2013) 55-68.

[44] H.M. Jennings, Colloid model of $\mathrm{C}-\mathrm{S}-\mathrm{H}$ and implications to the problem of creep and shrinkage, Mater Struct, 37 (2004) 59-70.

[45] S.-D. Wang, K.L. Scrivener, 29Si and 27AI NMR study of alkali-activated slag, Cem Concr Res, 33 (2003) 769-774.

[46] J.J. Chen, J.J. Thomas, H.F.W. Taylor, H.M. Jennings, Solubility and structure of calcium silicate hydrate, Cem Concr Res, 34 (2004) 1499-1519.

[47] S.A. Rodger, G.W. Groves, N.J. Clayden, C.M. Dobson, A Study of Tricalcium Silicate Hydration from Very Early to Very Late Stages, MRS Proceedings, 85 (1986) 13.

[48] L. Parrott, An examination of the effects of age at loading upon the creep of hardened cement paste, Magazine of Concrete Research, 25 (1973) 197-200.

[49] Z.P. Bažant, M. Jirásek, Microprestress-Solidification Theory and Creep at Variable Humidity and Temperature, Creep and Hygrothermal Effects in Concrete Structures, Springer2018, pp. 455-498. 
Accepted version. Published as: Wyrzykowski et al., Basic creep of cement paste at early age - the role of cement hydration. Cem Concr Res (2019) 116: 191-201

https://doi.org/10.1016/j.cemconres.2018.11.013

[50] Z.C. Grasley, K.R. Rajagopal, X. Li, Theoretical Basis for Dissolution-Induced Viscoelastic and Viscoplastic Behavior of Cementitious Materials, Multiscale Computational Modeling of Cementitious MaterialsKrakow, Poland, 2012.

[51] X. Li, Z.C. Grasley, J.W. Bullard, P. Feng, Creep and relaxation of cement paste caused by stressinduced dissolution of hydrated solid components, Journal of the American Ceramic Society, 101 (2018) 4237-4255.

[52] A.C.A. Muller, K.L. Scrivener, A.M. Gajewicz, P.J. McDonald, Densification of C-S-H measured by $1 \mathrm{H}$ NMR relaxometry, The Journal of Physical Chemistry C, 117 (2012) 403-412.

[53] L. Sorelli, G. Constantinides, F.-J. Ulm, F. Toutlemonde, The nano-mechanical signature of Ultra High Performance Concrete by statistical nanoindentation techniques, Cem Concr Res, 38 (2008) 14471456.

[54] K. Velez, S. Maximilien, D. Damidot, G. Fantozzi, F. Sorrentino, Determination by nanoindentation of elastic modulus and hardness of pure constituents of Portland cement clinker, Cem Concr Res, 31 (2001) 555-561.

[55] C. Famy, K.L. Scrivener, A.K. Crumbie, What causes differences of C-S-H gel grey levels in backscattered electron images?, Cem Concr Res, 32 (2002) 1465-1471.

[56] E. Gallucci, P. Mathur, K. Scrivener, Microstructural development of early age hydration shells around cement grains, Cem Concr Res, 40 (2010) 4-13. 